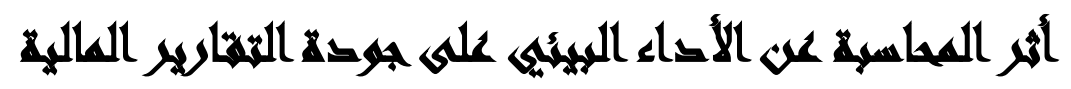

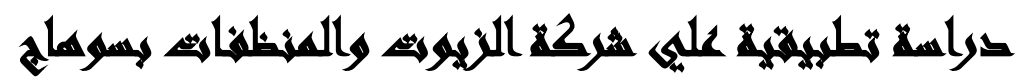

[IV]

\author{
جمال سعد الاين أحمد خطاب(')- نهال محمد فتحي الشحات(؟)

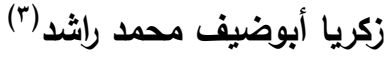

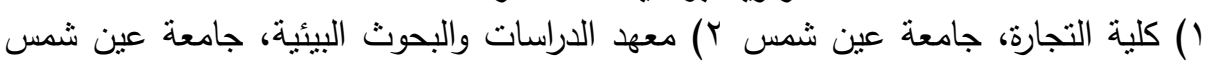

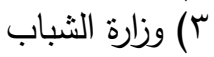

\section{المُمبنحلص}

تهدف هذه الدراسة إلى الاهتمام بالمحاسبة عن الأداء البيئي والذي سوف بساهم في

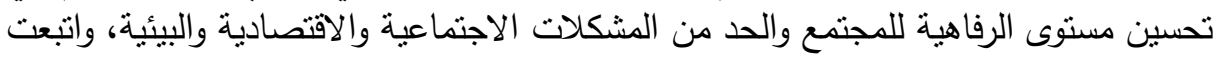

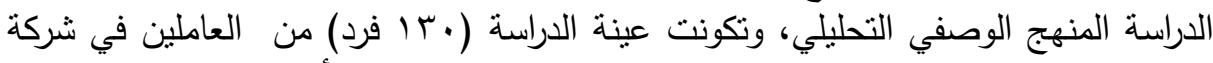

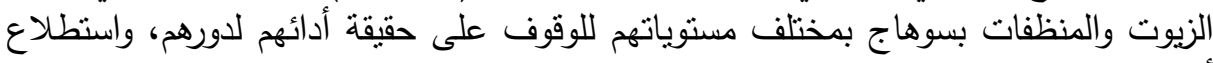

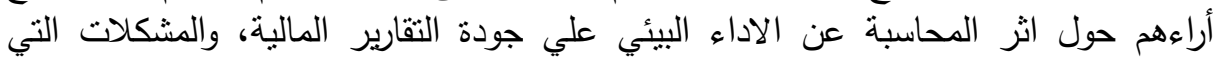

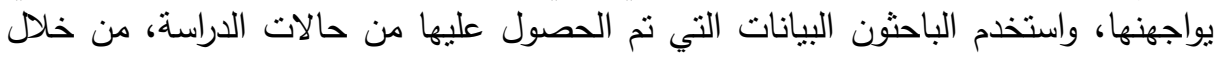

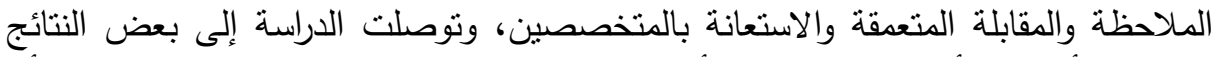

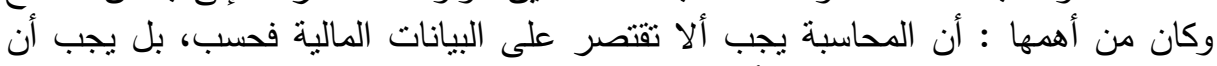

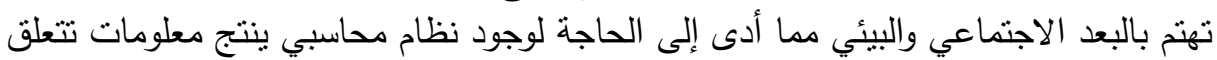

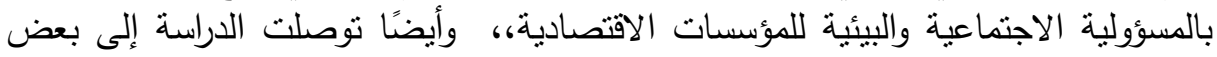

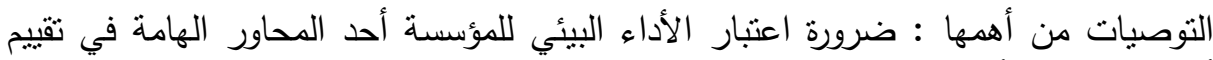

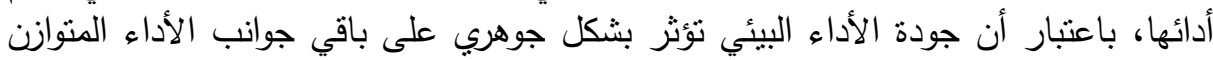

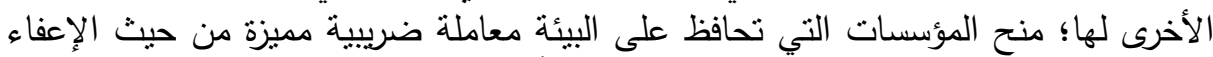
أو تخفيض الضرائب المفروضة لهينة عليها، وذلك تشجيعاً لها على حماية البيئة.

\section{هัl}

أصبحت حماية البيئة والمحافظة عليها إحدى أهم سمات النظام الدولي الجديد، تزايد في

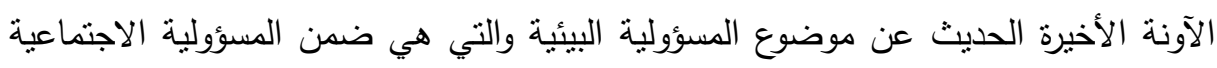

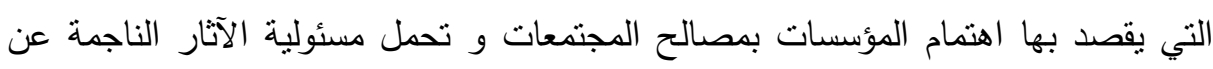

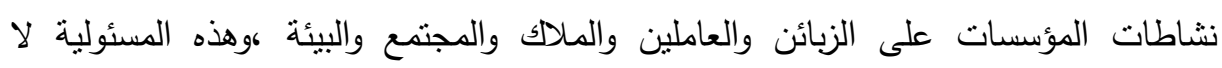

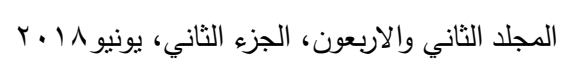


تقتصر فقط على الالتزامات القانونية بل تتجاوزها إلى تحسين العلاقة مع أصحاب المصلحة (أبو العزم فهيم).

ومن المفروض أن تكون المسئولية البيئية ضمن الخطط السنوية للمؤسسات بحيث تظهر

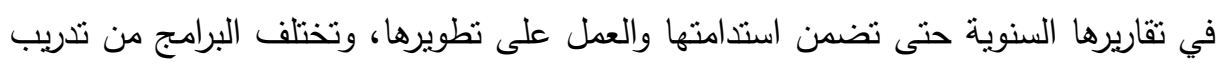
للعاملين إلى البرامج التعليمية إلى المساهمة في تطوير المتنزهات والمحميات وتشجيع المبادرات الاجتماعية والاهتمام بأسر العاملين ودعم المؤسسات الخيرية و الثركات الناشئةة.(محمد بدوي) وتعتبر ظاهرة التلوث البيئي من الظواهر التي تؤثر علي البيئة، خاصة في ظل التقدم

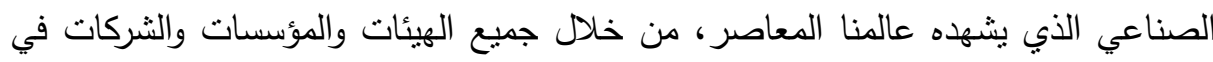

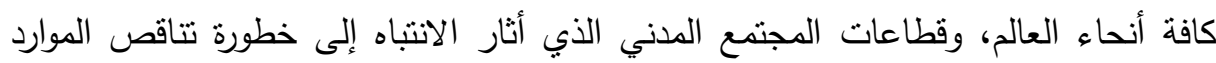
الطبيعية، وعمليات التلوث الحادثة بهذه الموارد، مما يؤدي إلى إهدار مستمر للأصول التهاه

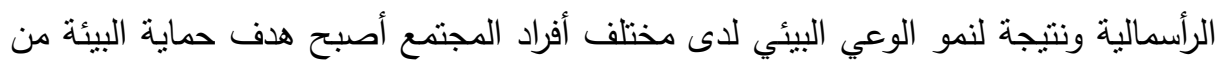
الأهداف الأساسية التي تسعى المؤسسة إلى تحقبقها، كما أدى تزايد الاهتمام بحماية الموارد

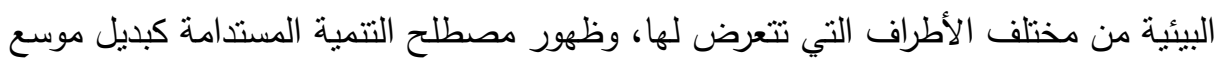

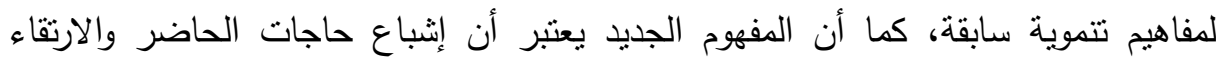
بالرفاهية الاجتماعية، لا يمكن أن يكون على حساب قدرة الأجيال القادمة في تلبية احتياجاتها

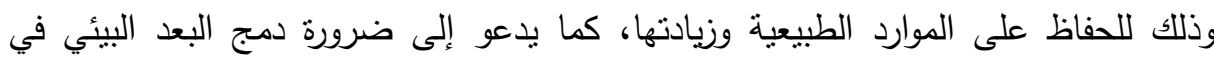
السياسات التتموية والاقتصادية والاجتماعية والاهتمام بالتتمية مع الأخذ بعين الاعتبار البيئة

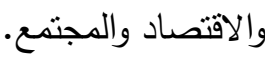

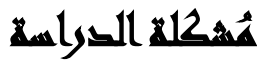

لم يعد اليوم في مصلحة المؤسسة سواء على المدى البعيد أو القصير إغفال الجوانب

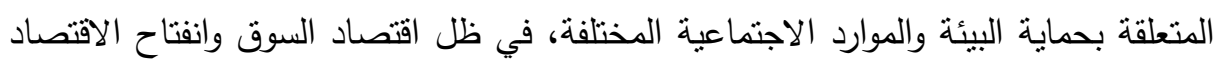
الوطني على الاقتصاديات الدولية، أصبحت المؤسسات الاقتصادية مطالبة بالاستجابة لنفس فله المتغيرات التي تؤثر على المؤسسات الاقتصادية في الدول الأخرى، و ذلك من أجل أن الن النهان 
يكتسب المنتج المحلي المواصفات التي تمكنه في اقتحام الاسواق الدولية من جهة، و لكي

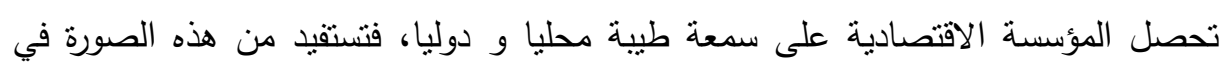

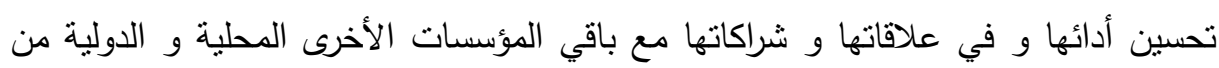
جهة أخرى. قام الباحثون باجراء دراسة استطلاعية علي عينة مكونه من (•r فرد) وذلك للاجابة

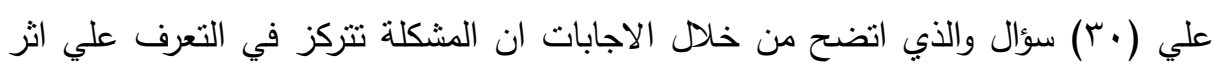

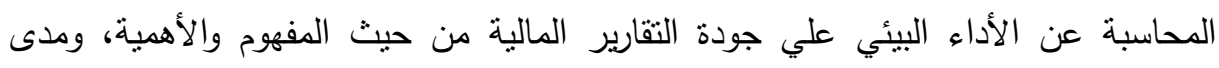

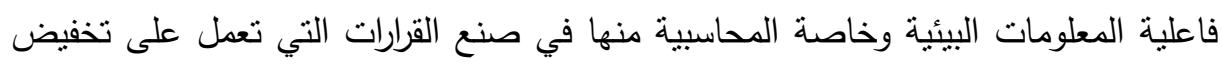
الخطر أو معالجته من خلال ثقديم المعلومات الاقتصادية والمحاسبية اللازمة . لألك سيكون السوأل الرئيسي المطروح في البحث: ما أثز المحاسبة عن الأداء البيئي على جودة النقارير المالية في شركات الزيوت والمنظفات ؟ وتتفرع منه الأسئلة الثانوية التالية :

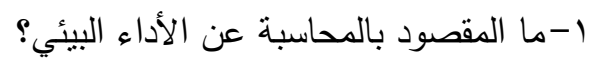

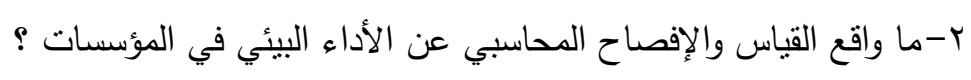

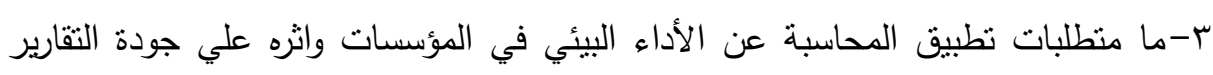
المالية؟

\section{أهمية التصواسمة}

تتبع أهمية الدراسة من الأهمية المتزايدة للمسؤولية الاجتماعية والبيئية، حيث أصبح

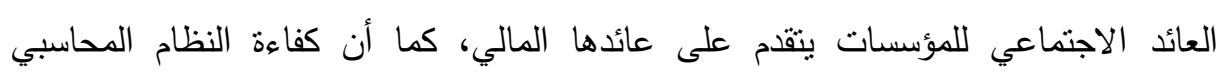
أصبحت تقاس بمدى احتوائه على نظام فرعي يتيح الحصول على معلومات عن الأداء البيئي

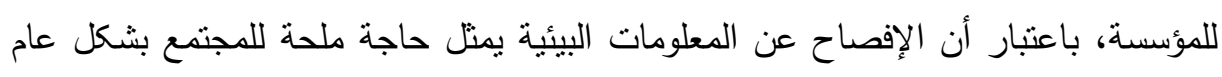

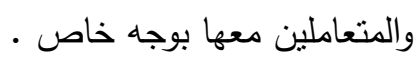


تأتي أهمية الاراسة الحالية من خلال ما يلي: • الأهمية العلمية: تتدر الأبحاث والدراسات في المكتبة العربية التي اهتمت بدارسة أثنر المحاسبة عن الأداء البيئي على جودة التقارير المالية والتطبيق علي شركة النيل للزيوت الابت ولثيه

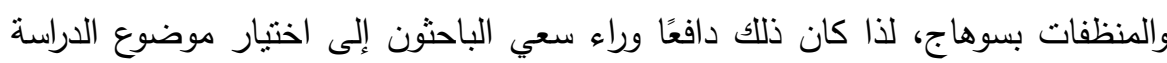
أملًا منه في أن تسهم هذه الدراسة في إضافة لبنة إلي المكتبة العربية في هذا المجال. • الأهمية النظرية: يمثل البحث الحالي إضافة نظرية لمجموع الدراسات التي نظرح الموضوعات الخاصة باثر المحاسبة عن الاداء البيئي علي جودة التقارير المالية.

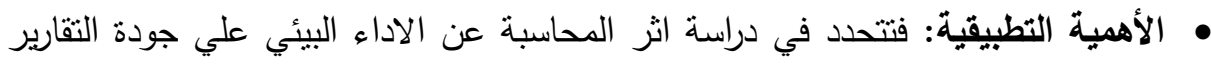
المالية علي شركة النيل للزيوت والمنظفات . ومن هنا تأتي أهمية الدراسة الحالية في أنها تعالج موضوعًا هامًا يتعلق باثر المحاسبة

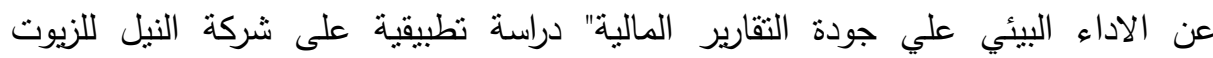

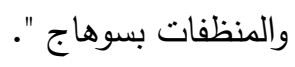

\section{أهساهت التراسة}

تسعى هذه الاراسة إلي تحقيق مجموعة من الأهداف يمكن بلورتها في الآتي

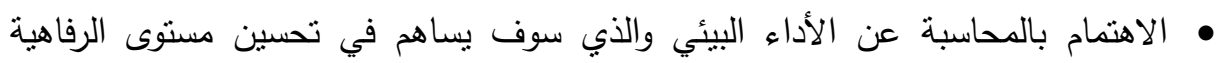
للمجتمع والحد من المشكلات الاجتماعية والاقتصادية والبيئية.

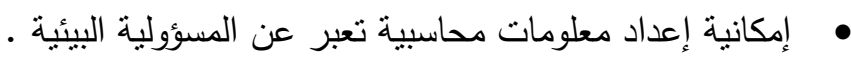

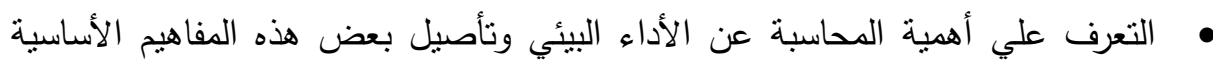
للأداء والبيئي. • محاولة تصميم نموذج محاسبي يخدم شركات الزيوت والمنظفات لقياس تكلفة الأداء البيئي. • تطبيق بعض الأسس والمعايير التي وضعت من قبل الباحثونين والمنظمات الدولية لقياس المحاسبة عن الأداء البيئي وأثرها على جودة التقارير المالية. 
تقبيم الأداء البيئي للمنظمة وذلك من خلال تحديد ما إذا كانت استراتيجية المنظمة وأهدافها تتماشى مع الأولويات الاجتماعية من جهة ومع طموح المنظمة للأفراد بتحقيق نسبة معقولة من الأرباح من جهة أخرى وتمثل العلاقة بين أداء منظمات الأعمال الاقتصادية والرفاهية الاجتماعية العنصر الجوهري لهذا الهدف من أهنداف أهداف الهحاسبة الاجتماعية والبيئية ويرتبط هذا الهدف أيضا بوظيفة القياس المحاسبي.

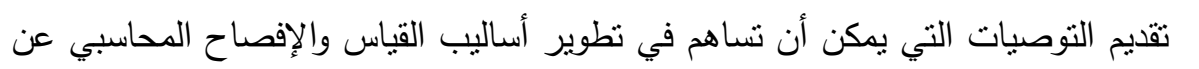

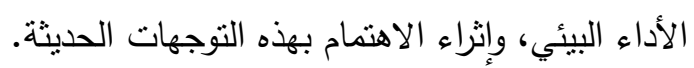

\section{هروضر الصواسما}

اتساقا مع تساؤلات الدراسة فإن الباحثونون يعرضون عدة فروض يحاول من خلال

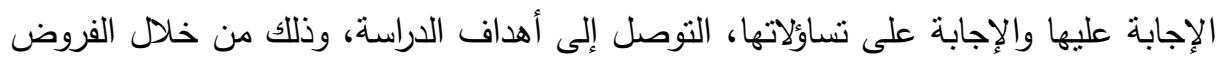
الآتية : • توجد علاقة معنوية ذات دلالة إحصائية لأبعاد المحاسبة عن الأداء البيئي وجودة التقارير المالية. • - - توجد علاقة أنز ذو دلالة إحصائية لأبعاد المحاسبة عن الأداء البيئي علي جودة التقارير المالية.

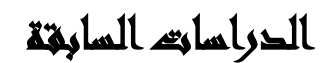

اطلع الباحثون علي العديد من الدراسات السابقة ذات الصلة بموضوع البحث، وفيما

$$
\text { يلي تلخيص لأهم هذه الدراسات : }
$$

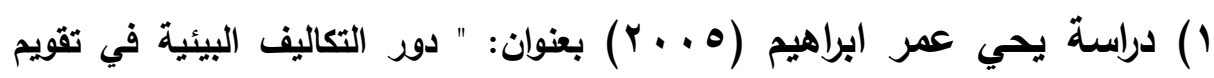

الاداء البيني في المنشآت الصناعية اليمنية ".

تمثلت مشكلة الدراسة في ضعف الاهنمام بالاداء البيئى فى المنشأت الصناعية في الهئي الجمهورية اليمنية، وابراز دور التكاليف البيئية في تقويم اداء المنشأت الصناعية اليمنية باداء لهئية وهدفت الدراسة الى التعرف على مدى فعالية الاداء البيئي في المنشأت الصناعية اليمنية،

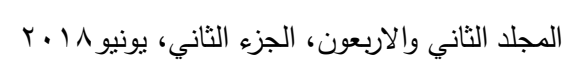


وتحديد الصعوبات التي تواجه عمل الاداء البيئى فى المنشآت الصناعية اليمنية، وتحديد العوامل التى تساعد على رفع كفاءة الاداء البيئي في المنشآت الصناعية اليمنية. انتهت الدراسة إلى توصيات أهمها: • ضرورة تطبيق محاسبة التكاليف البيئية في المنشأت اليمنية حتى تسنطيع المنتجات اليمنية المنافسة في الاسواق العالمية. • ضرورة اهتمام المنشآت اليمنية بالبيئة والمحافظة عليها ومنع التلوث بكل أنواعه واشكاله، والالتزام بما يسمى بالانتاج النظيف.

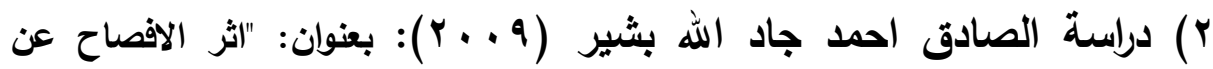

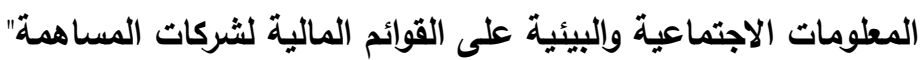
تمثلت مشكلة الدراسة في: ان الثركات المساهمة والمسجلة في سوق الخرطوم للاوراق المالية لا تقوم بمسئوليتها الاجتماعية والبيئية في قوائمها المالية وهدفت الدراسة لبيان دور الافصاح الطوعي في تحسين جودة المعلومات وبيان مدى تأثثر الافصاح الطوعي عن المعلومات الاجتماعية والبيئية على القوائم المالية، وبيان دور الافصاح القوي عن نللك المعلومات في لئي اظهار دور المؤسسات في المساهمة الاجتماعية والبيئية وتقويم الاداء الاجتماعي والبيئي ومدى فاعلية وكفاءة الشركات المساهمة في الوفاء بمسئوليتها الاجتماعية والبيئية تجاه المجتمع من أهم نتائج الاراسة ان: الالتزام بالافصاح الطوعي عن المعلومات الاجتماعية والبيئية في القوائم المالية يؤثر على مصداقيتها وملائمتها، وان المعلومات المفصح عنها طوعاً فى القوائم المالية تتصف بالمصداقية والثفافية والملائمة. من أهم توصيات الدراسة: تحفيز الثركات التى تفصح طوعاً عن المعلومات الاجتماعية

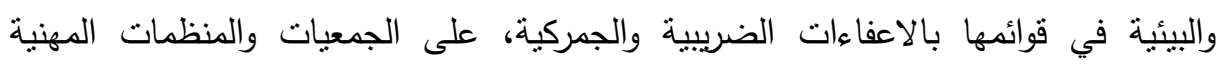

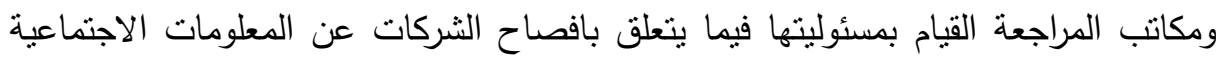




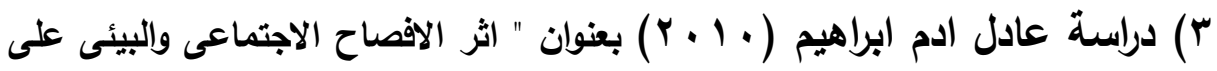

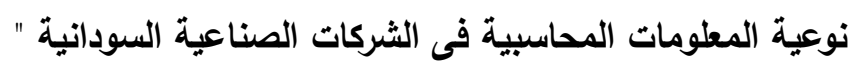

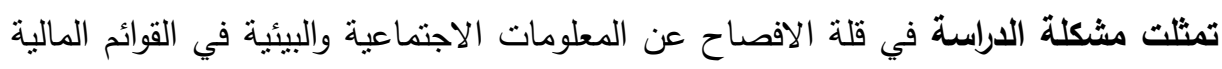

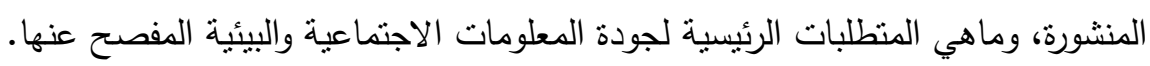

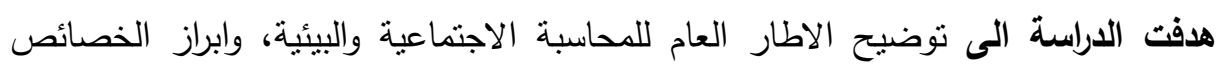
الاساسية لجودة المعلومات الاجتماعية والبيئية.

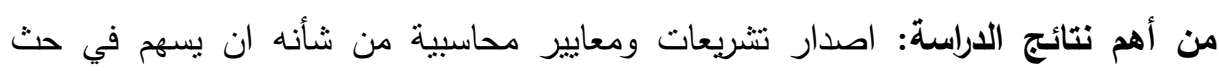

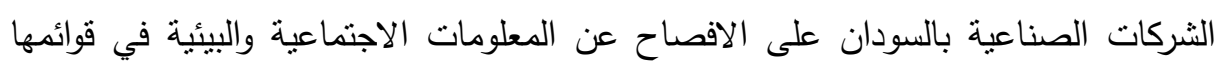

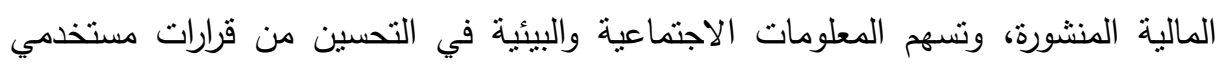

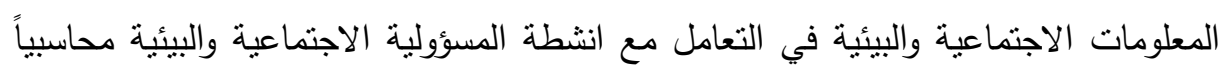

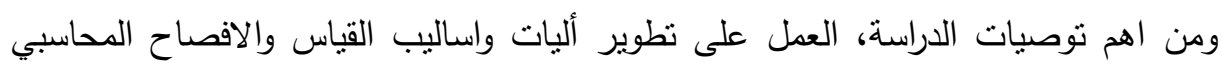

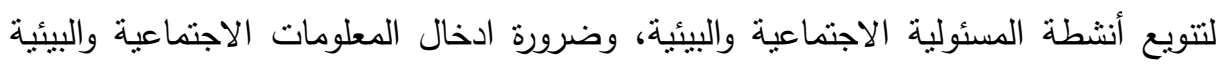

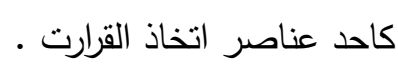

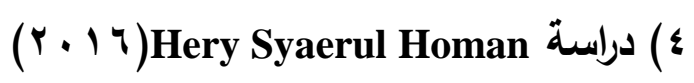
بغنوان:" Environmental Accounting Roles in Improving The Environmental Performance And Financial Performance of The Company تمثلت مشكلة الدراسة في مدي تفعيل دور الدحاسبة البيئية في تحسين الاداء البيئي والمالي

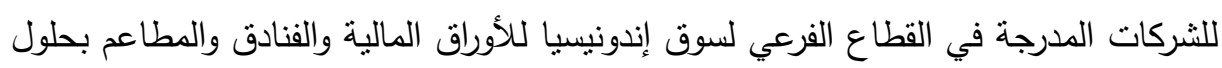

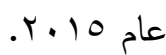
هلافت الداسة إلى: تحديد كيفية دور المحاسبة البيئية في التحسين الأداء البيئي والأداء

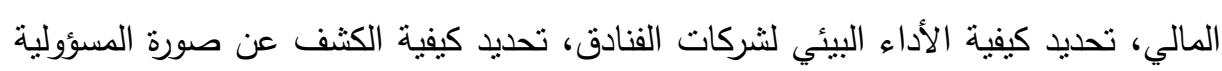

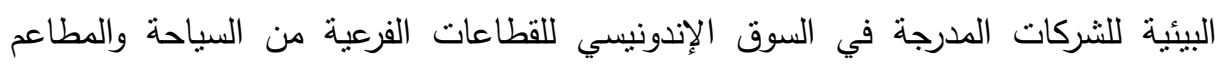

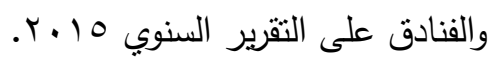


أهم النتائج: يؤدي فهم القضايا البيئية إلى توجيه الشركة في سياساتها، وخاصة فيما يتعلق

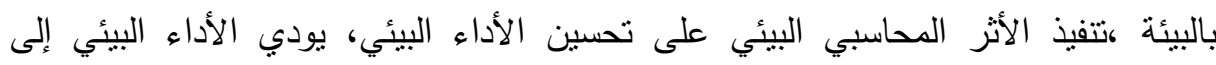

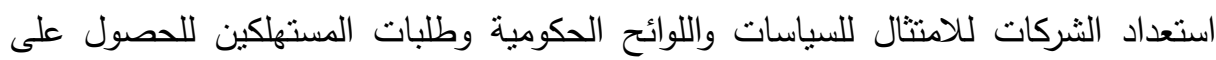

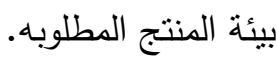
من أهم التوصيات للاراسة: اصدار تشريعات تلزم المنشأت بتطبيق المحاسبة البيئية وعرض التكاليف البيئية في القوائم المالية، وتبني الادارة والقائمين على النظام المحاسبي في الثركة لتصنية ادراج خريطة حسابات جديدة هدفها توفير بيانات ومعلومات عن تكاليف الاداء البيئي والمنافع التي يمكن تحقيقها من برامج تحسين الاداء البيئي وتطوير للشركة. أوجه الاختلاف بين الاراسة والدراسات السابقة:

اختلفت الدراسات السابقة مع الدراسة الحالية في عدة نقاط أهمها: ا- تتاولت هذه الدراسة شئ لم تتطرق اليه الدراسات السابقة وهو دراسة شركة الزيوت والمنظفات.

r- تتاولت الدراسة أثز المحاسبة عن الأداء البيئي علي جودة التقارير المالية من خلال تحليل واف وشرح مفصل وهو ما لم تنتاوله الدراسات السابقة. r- من خلال مراجعة الادبيات التي تتاولت الاداء البيئي واثره علي جودة التقارير المالية تبين قلة المراجع المتخصصة في هذا المجال في المكتبة العربية حيث اتضح ان معظم إنم الدراسات التي تتاولت هذا الموضوع ركزت علي الاداء الاجتماعي واغفلت الاداء البيئي. ع-إيراز معالم الثريعة الإسلامية في موضوع حماية البيئة من الثلوث. أوجه استفادة الباحثون من الاراسات السابقة: ا ـ تكوين بناء معرفي حول البيانات والمعلومات ذات الصلة بموضوع الدراسة، سواء الخاء الخاصة بالمحاسبة عن الاداء البيئي او الخاصة بجودة التقارير المالية.

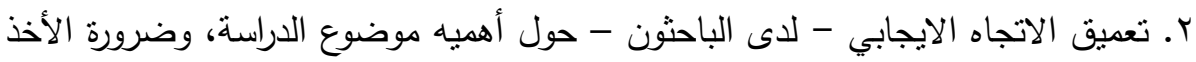
بكل ما هو جديد لفهم المحاسبة البيئية واثزها علي المجتمع. 
r. أهمية دراسة أثز المحاسبة عن الاداء البيئي علي جودة الثقارير المالية لكي يستفاد منه متخذي لقرارات.

ع. استفادة من النتائج التي انتهت إليها تلك الدراسات السابقة، وتلافي الأخطاء في تلك الدراسات.

أهم ما يميز هذه الدراسة عن الاراسات السابقة: من خلال الاطلاع على الدراسات السابقة

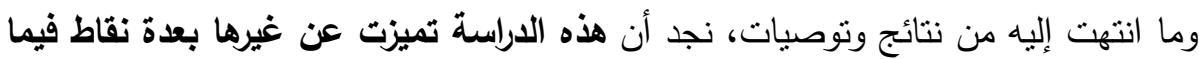
يلي:

• تتاول الدراسة الحالية دراسة أثز المحاسبة عن الاداء البيئي علي جودة التقارير المالية من خلال تحليل واف وشرح مفصل وهو ما لم تتتاوله الدراسات السابقة. • يثير الباحثون لأهمية المشاركة المجتمعية في مواجهة تلوث وهو البيائية.

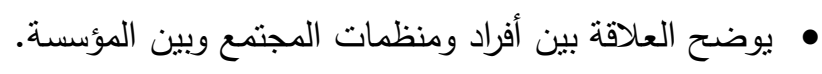

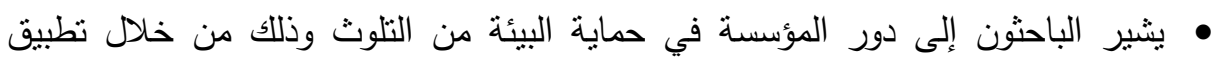

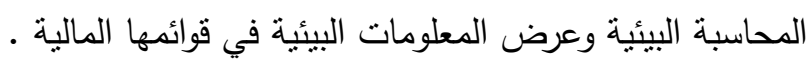

\section{الإطالر النهظيى}

\section{גall}

المحاسبة عن الاداء البيئي:

المبحث الاول: المفاهيم الاساسية للبيئة ومعايير حمايتها: • مفهوم البيئة: نعني كلمة البيئة في اللغة العربية مكان الإقامة أو المنزل أو المحيط، وهي

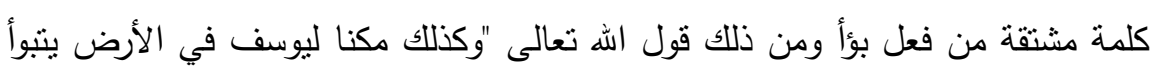

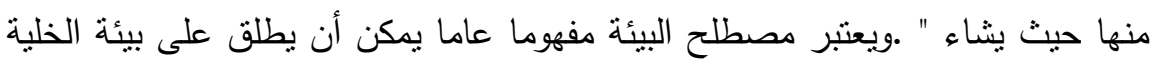

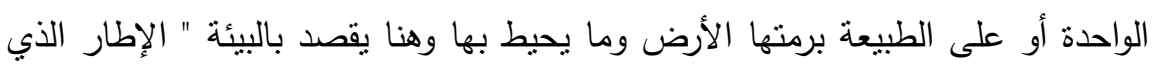

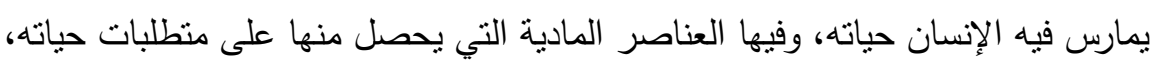

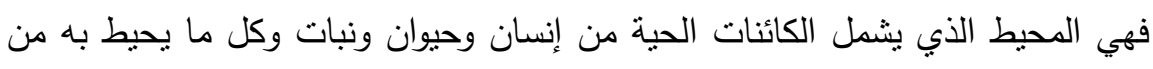

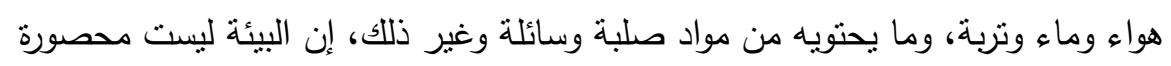


في الموارد البيئة الطبيعية التي خلقها اله للإنسان لكي يحصل منها على مقومات حياته فحسب، بل تتمل أيضا الموارد التى وضعها الإنسان (البيئة الوضعية أو المشيدة).

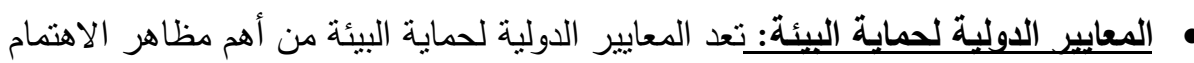

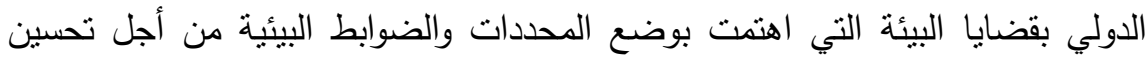

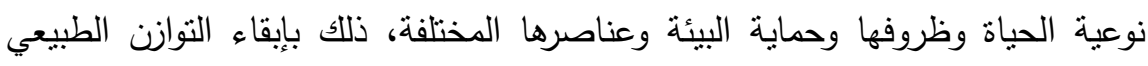
ولتحقيق التتمية الاقتصادية والاجتماعية، وتحقيق مفهوم الإدارة السليمة لعناصر البيئة،

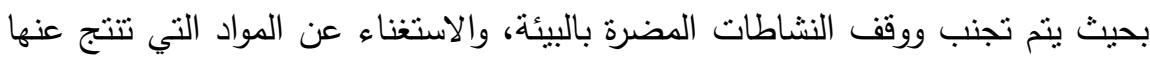
أخطار بيئية فهنالك المعايير الاقتصادية، التجارية والقانونية التي تعمل علي حماية البيئة.

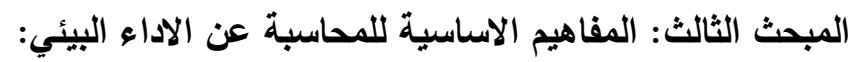
• مفهوم المحاسبة عن الاداء البيئي:ارتبط ظهور المحاسبة البيئية بظهور المسؤولية البيئية التي تمنل جزءا من المسؤولية الاجتماعية للمشروع والتي تضم جميع الأنشطة

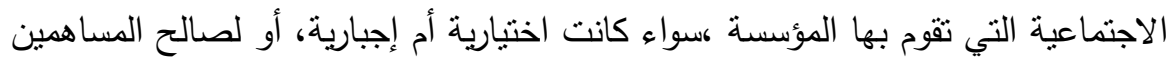
أو العاملين أو المجتمع بصفة عامة، ويمكن تعريف المحاسبة عن الأداء البيئي بأنها" العلاقة المنبادلة بين المحاسبة والبيئة، تهدف إلى إنشاء نظام معلومات بيتي داخل نهل المؤسسات، يمكنها من مراعاة وإدراج البيئة وقضاياها في العديد من القرارات التي يستفيد

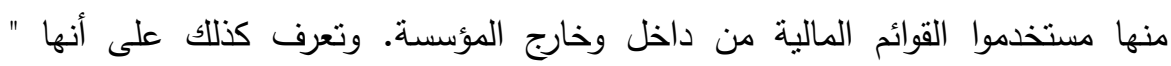
مجموعة ممارسات تتم في المؤسسة إما على المستوى الوطني، أو على مستوى المؤسسة فحسب، تقود إلى فهم وإدارة جيدة للجوانب البيئية وما يتبعها من تكلفة وعرفها معهد البها

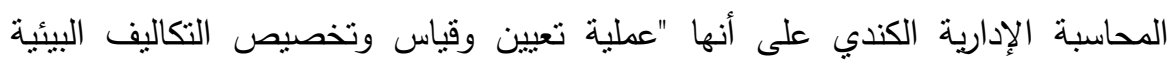
لأخذها في الاعتبار عند اتخاذ القرارات الإدارية ثم توصيل المعلومات لمستعمليها ويمكن تعريفها بأنها " إدارة الأداء البيئي والاقتصادي من خلاد تهيئة وتطوير نظم محاسبيه ملائمة تتعلق بالبيئة وتطبيقاتها ـ وتتضمن عادة عملية التقرير والتدقيق المحاسبي ولاهي بالإضافة إلى احتوائه على عمليات تكلفة دورة الحياة والمحاسبة عن التكلفة الكلية وتقييم المنافع والتخطبط الإستراتيجي لإدارة البيئة.

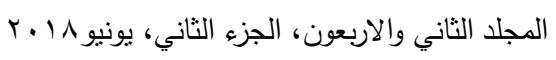




\section{أساسيات المحاسبة عن الاداء البيئي:}

المبحث الاول: متطلبات تطبيق المحاسبة عن الأداء البيئي والافصاح عنها: توفير قواعد للنظام المحاسبي البيئي: عن طريق توفير حد أدنى من القواعد التي تلائم

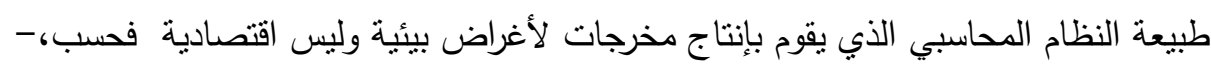
توفير معايير للتقدير المحاسبي البيئي: ان توفير معايير تلائم إعداد القوائم البيئية، وخاصة في حالة انفصالها عن القوائم المالية

التقليدية ولعل ذلك يساهم في الاهتمام بنوعية البيانات التي تنملها القوائم البيئية. خطوات تطيق المحاسبة عن الأداء البيئي: ينم تطبيق المحاسبة عن الأداء البيئي من خلال النظام المحاسبي للمؤسسة بالمرور عبر المراحل والإجراءات الآتية:

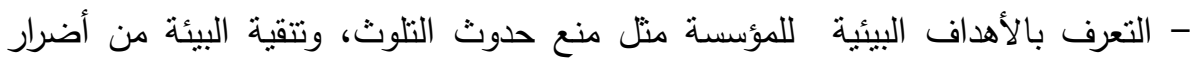
المؤسسة وغيرها.

- تحديد الأطراف المستقيدة من التقارير عن الأنشطة البيئية.

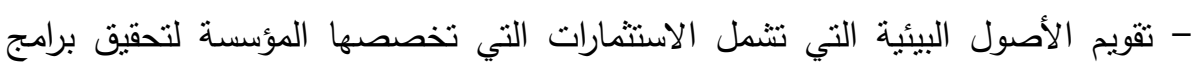

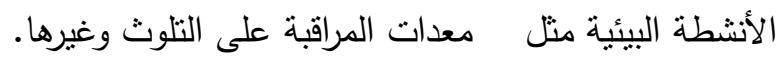

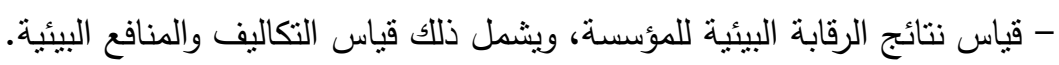

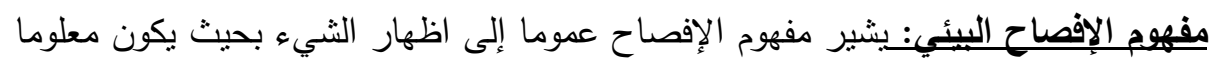
وواضحا، والهدف الرئيسي للإفصاح هو توفير المعلومات التي تفيد مختلف الطوائف عند

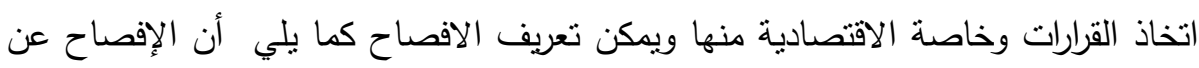

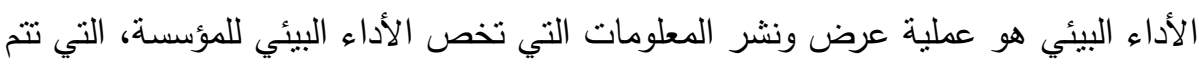

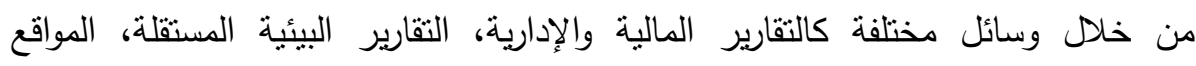
الإكترونية أو المؤتمرات أو الصحف، وذلك لتمكين مختلف أصحاب المصالح من الحصول على المعلومات اللازمة للتخطيط والرقابة وتقييم الأداء. 
المبحث الثاني: اصدارات المنظمات والهيئات المختصة عن محاسبة الاداء البيئي.

إصدارات الهيئات الدولية منها: مؤتمر الأمم المتحدة للتجارة والتنسية: UNCTAD بادر فريق عمل الخبراء الحكوميين حول المعايير الدولية للدحاسبة والتقرير ISAR الذي انبثق عن مؤتمر UNCTAD إصدار

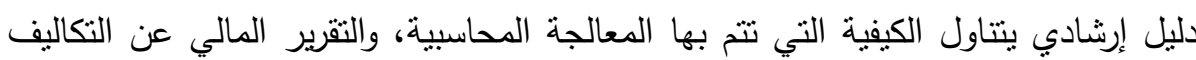
والالتزامات البيئية.

إصدارات الهيئات الإقليمية، منها: منظمة التعاون الاقتصادي والتنمية: OECD أصدرت المنظمة دليل إشادي خاص

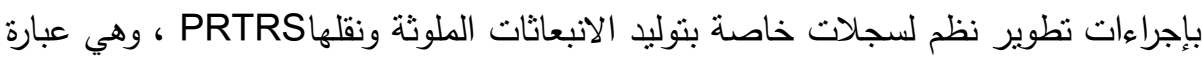
عن دفاتر جرد متمثل قاعدة بيانات متاحة للجميع حول الانبعاثات من المواد المضرة التي لهي

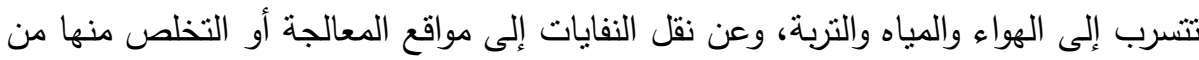

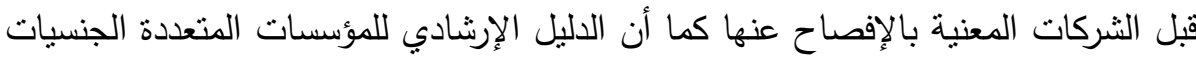

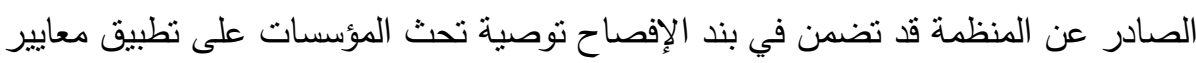

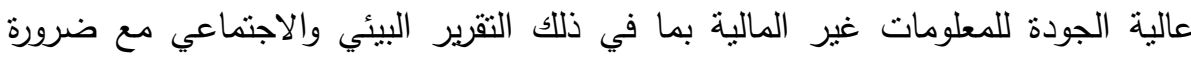

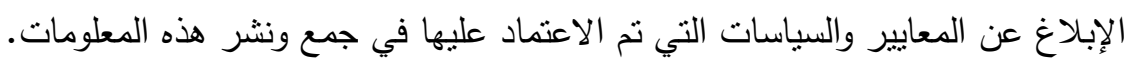

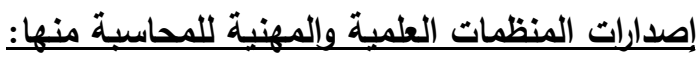
الإتحاد الدولِي للمحاسيني: IFAC أصدر الإتحاد المعيار الدولي للتدقيق رقم 1010 بعنوان

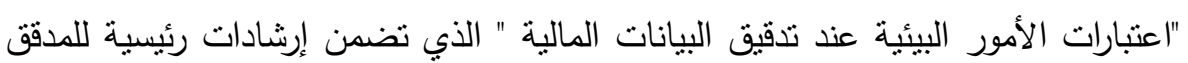

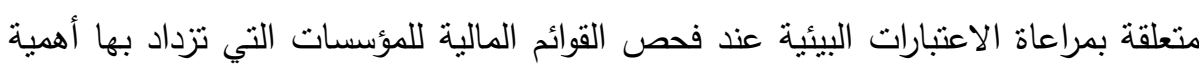
الأمور البيئية التي من شأنها التأثير على القوائم المالية. 


\section{جودة التقارير المالية:}

المبحث الاول: مفهوم وخصائص جودة التقاريز المالية:

مفهوم جودة التقارير المالية:تعني الجودة في هذا المجال مصداقية المعلومات المحاسبية

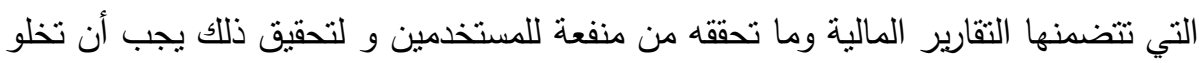
من التحريف والتضليل وأن تعد في ضوء مجموعة من المعايير القانونية والرقابية والمهنية

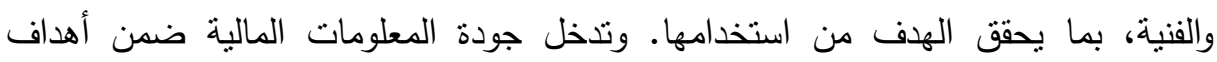

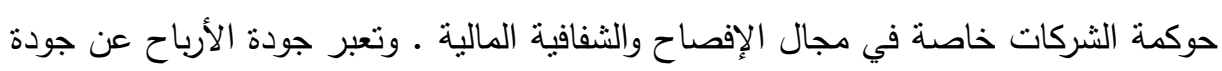
التقارير المالية كما أنها حظيت باهتمام كبير من قبل المستثرين والمنظمات الماتهاح المهنية والباحثونين والممارسين خاصة بعد حدوث الأزمة المالية العالمية الأخيرة بصفة عامة ولفير وانهيار

بعض الشركات بصفة خاصة. تتمثل هذه الخصائص:

الملاعمة: تعني ملاءمة المعلومات المالية قدرتها على إحداث فرق في القرارات السابقة

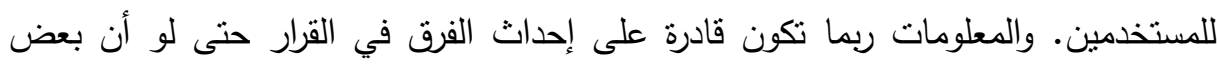

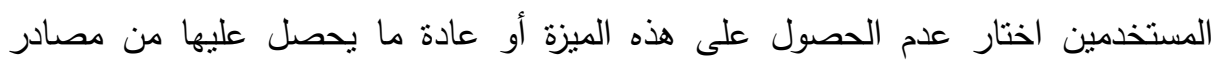
أخرى. يمكن للمعلومات المالية إحداث الفرق في القرارات إذا نوافرت لها القيمة التبات التبؤية، والقيمة المؤكدة أو الاثثنان معا. لمعات المعات التمثيل الصادق:تعد التقارير المالية تمثيل للظواهر الاقتصادية من خلال الكلمات والأرقام، كما أن تحقيق المعلومات المالية المفيدة لا يقتصر على ملاعمة الظواهر ولكن يتتاول التمثيل

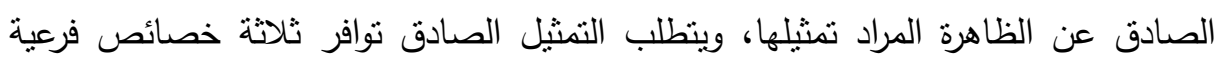
هي: الاكتمال، الحياد، والخلو من الأخطاء، و بطبيعة الحال يكون الكمال نادراً، ونتيجة

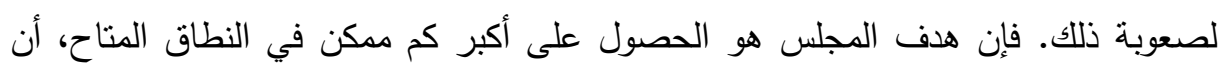

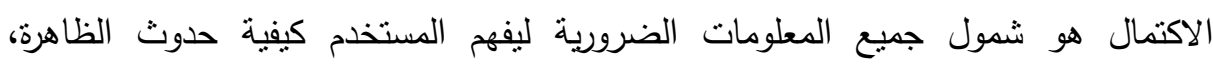
وضرورة أن تتشل جميع التوصيفات والتفسيرات. 
المبحث الثاني: أنواع جودة التقارير المالية ومداخل تقييمها: أنواع جودة التقارير المالبة: - جولة صياغة التقريز: توصيف بيانات التقرير بشكل جيد بحيث تكون الكلمات المختارة لوصف البيان واضحة ومفهومة ومعبرة بدقة عن البيان ويتطلب هذا توافر خاصية الوضوح.

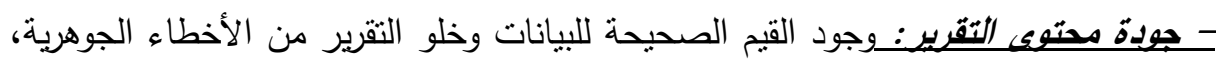
وينطلب هذا نوافر ثناث خصائص هي الشمول والاكتمال والدقة.

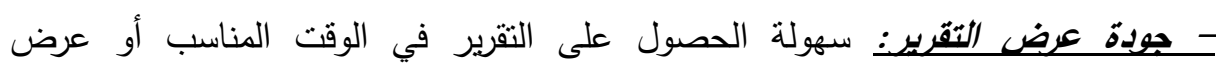

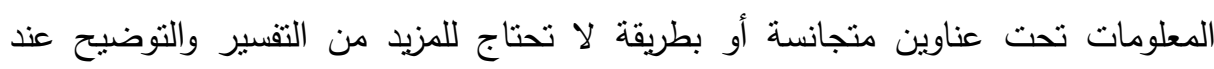
استخدامها، وينطلب هذا نوافر أربع خصائص هي الاتساق أو الثبات والحياد والتوقيت والثفافية.

\section{مداخل جودة التقاريز المالية:}

- ملذل /حتياجات المستخلم:نركز هذه المجموعة علي قضايا التقييم، وتعني جودة التقارير المالية وفقاً لهذه المجموعة توفير احتياجات مستخدمي القوائم المالية ومقدار استقادتهم من المعلومات المالية التي تحتويها تلك القوائم، وينتمي لهذه المجموعة المدخلين التاليين : الإطار المفاهيمي لمجلس معايير المحاسبة المالية الأمريكي ومنهج لجنة جنكنز Jenkins Committee Approach - مدخل حمابة المساهم أو المستثمر:تركز هذه المجموعة علي تتظيم التقارير والرقابة كما تهنم باحتياجات المستثمرين من المعلومات لاتخاذ قرارات الاستثمار • وينم الحكم علي جودة المعلومات المحاسبية وبالتالي جودة التقارير المالية من خلال مدى توافر معلومات واضحة وكاملة أي يهتم فقط بخاصية واحدة لجودة معلومات القوائم المالية وهي الإفصاح العادل والكامل للقوائم المالية ـ ومن ثم تهنم هذه المجموعة بالتأكد من توفير كافة المعلومات. - مدظل ثقة الطرف الثالث في القوائم العالية: لا يعمل المحاسب من أجل الثركة التي

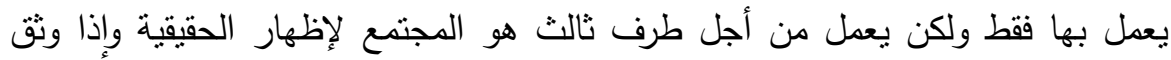
الطرف الثالث في القوائم المالية فيمكن الحكم عليها بأنها جيدة. 


\section{إجباءايه التراسمة}

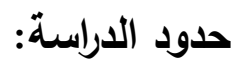

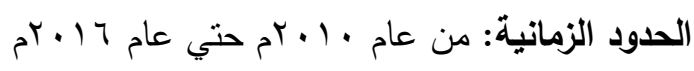
الحدود المكانية: النطاق المكاني للدراسة شركة النيل للزيوت والمنام المنظفات بمحافظة سوهاج.

\section{منهمج الترواسها}

في سبيل تحقيق هدف الدراسة واختبار فروضها، اعتمد الباحثون في هذه الدراسة الدنهج الوصفي التحليلي وأسلوب الدراسة الميدانية لجمع المعلومات والبيانات اللازمة لإتصام الدراسة. أما مصدر البيانات فقد تم العصول عليها من مصدرين هما:

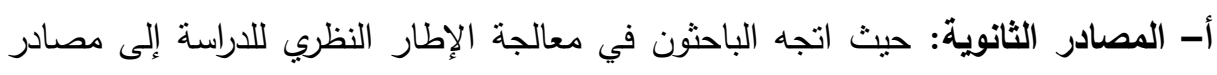

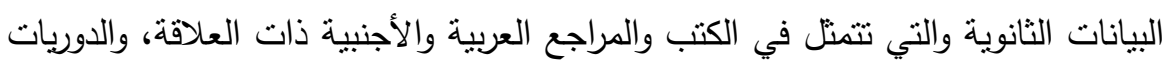

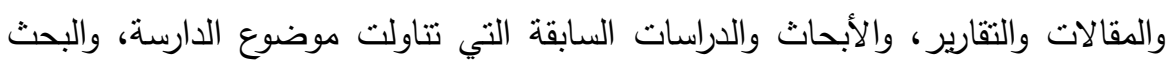
والمطالعة في مواقع الإنترنت المختلفة.

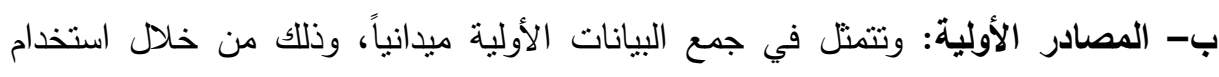

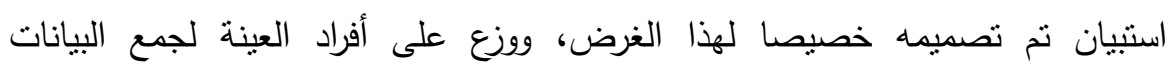

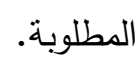

ميدان الدراسة: تم إجراء هذه الدراسة على العاملين في مجال الدحاسبة بشركة النيل للزيوت والمنظفات. وقا تألفت عينة الاراسة من: العنة

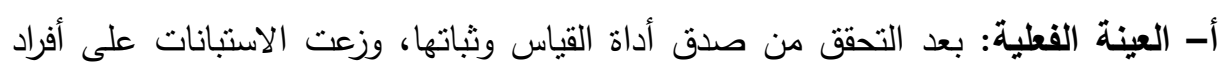

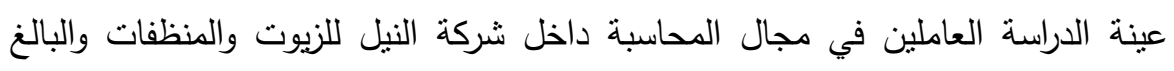

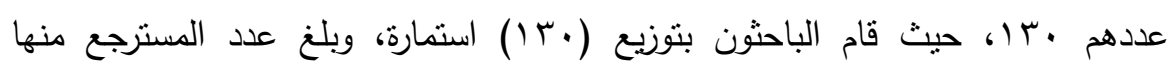

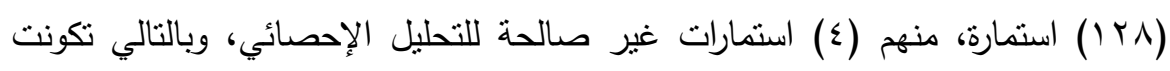

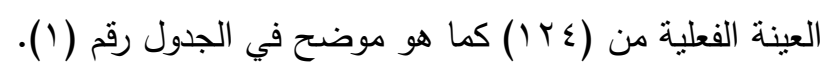




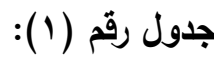

\begin{tabular}{|c|c|c|c|}
\hline العينة الفعلية & غير الصالحة & عدالد الاستمارِّت & عدد الاستمارات \\
\hline ITE & $\varepsilon$ & $1 Y 1$ & $1 \%$. \\
\hline
\end{tabular}

ب- أداة القياس: اعتمدنا في دراستتا الحالية على الاستبيان كأداة من أدوات جمع البيانات

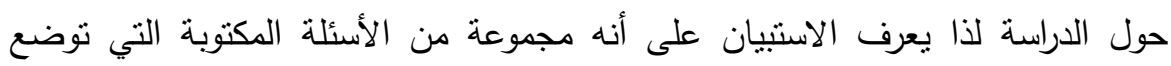

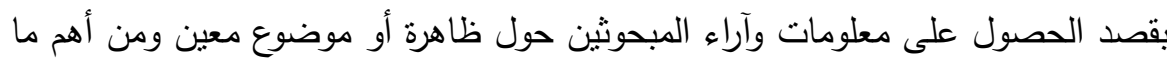
تتميز به الاستبانة هو توفير الكثير من الوقت والجهد على الباحثون، وعلى هذا الأساس

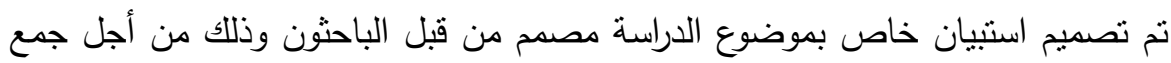
البيانات والمعلومات الخاصة بموضع الدراسة.

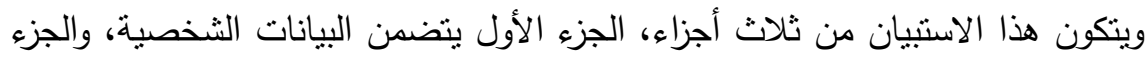

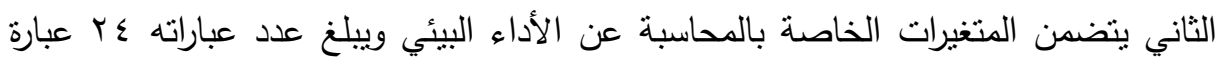
مقسمة على ثلاث أبعاد، والجزء الثالث بتضدن البنود الخاصة بجودة التقارير المالية وبيلغ

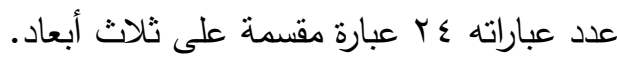
أما البدائل التي تم استعمالها في كلا الثقين فهي بدائل واحدة وهي تهاده بدائل: موافق بشدة، موافق، محايد، غير موافق، غير موافق بشدة. ج -الخصائص السيكومترية لأداة القياس: للتأكد من أداة الدراسة المستخدمة تستطيع أن بوان تقيس ما وضعت من أجله لتقبسه يجب قياس الخصائص السيكومنرية لهذه الأداة وهذه الخصائص نتمنل في الصدق والثبات وسنتطرق إلى كيفية حساب كل خاصية من هاتين

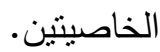

خصائص العينة: وفيما يلي عرض لعينة الدراسة وفق الخصائص الديموغرافية.

\begin{tabular}{|c|c|c|}
\hline النسبة المئوية \% & الكعد & المؤهل العلمى \\
\hline$\% \wedge 1,0$ & 1.1 & بكالور \\
\hline$\% \wedge, 1$ & 1. & دبلوم عالي \\
\hline$\% \curlyvee, 乏$ & $\Lambda$ & ماجستير \\
\hline$\% \varepsilon$, & 0 & دكتوراه \\
\hline$\% 1 \ldots$ & $T K \varepsilon$ & 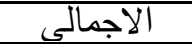 \\
\hline
\end{tabular}


من خلال استعراض الجدول رقم (Y) الخاص بتوزيع أفراد عينة الدراسة حسب متغير المؤهل العلمي، يتبين أن فئة المؤهل العلمي (بكالوريوس) يمثلون ما نسبته

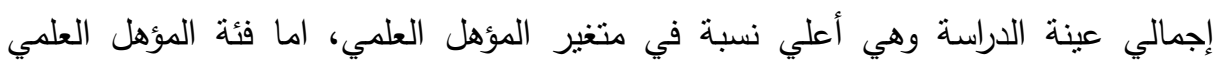
(دكتوراه) فيمنلون ما نسبته ؛ م من إجمالي عينة الدراسة وهي أقل نسبة في متغير المؤهل

جدول رقم(ץ): يوضح توزيع افراد العينة حسب متغير التخصص

\begin{tabular}{|c|c|c|}
\hline النسبة المئوية \% & العدد & التخصص \\
\hline$\% \vee 1, \cdot$ & $\Lambda \Lambda$ & محاسبة \\
\hline$\%$ \%r., l & To & مالية \\
\hline$\% \wedge, 9$ & 11 & إدارة آعمال \\
\hline$\% 1 \ldots$ & TYE & الإجمالي \\
\hline
\end{tabular}

من خلال استعراض الجدول رقم (r) الخاص بتوزيع أفراد عينة الدراسة حسب متغير

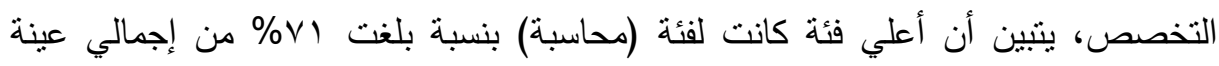

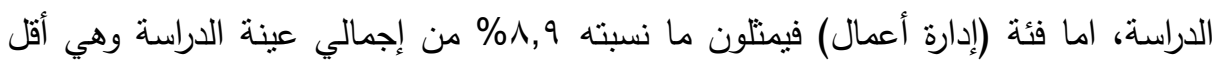
نسبة في متغير التخصص. جدول رقم(؛ ): يوضح توزيع افراد العينة حسب متغير الخبرة الوظيفية

\begin{tabular}{|c|c|c|}
\hline النسبة المئوية \% & العدد & الخبرة الوظيفية \\
\hline$\% \backslash \Gamma, V$ & IV & آلقل من ه سنوات \\
\hline$\% r r, r$ & $\xi$ & من ه إلى أَقل من • 1 سنة \\
\hline \%үч, & Tr & من • 1 إلى آقل من 10 سنة \\
\hline$\% \backslash \wedge, 0$ & Tr & من 10 إلى آقل من ·r سنة \\
\hline$\% \wedge, 9$ & 11 & أكثر من ·r سنة \\
\hline$\% 1 \ldots$ & TY乏 & الإجمالى \\
\hline
\end{tabular}

من خلال استعراض الجدول رقم (ع) الخاص بتوزيع أفراد عينة الدراسة حسب متغير

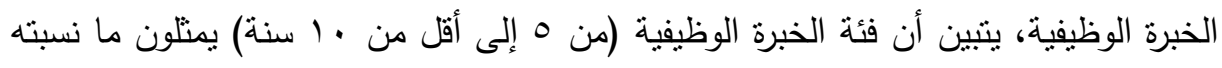

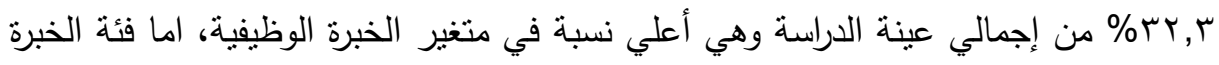

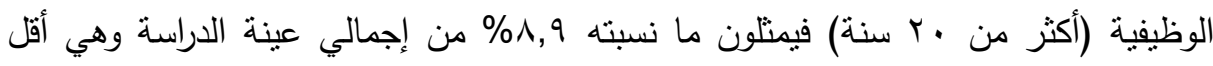
نسبة في متغير الخبرة الوظيفية. 
تصميم أداة الدراسة: قام الباحثونون بصياغة أولية لعبارات المقياس المستخدم انطلاقا من موضوع الدراسة وأهدافها وتساؤلاتها وذللك بعد القراءة المتأنية والاطلاع على الأدبيات

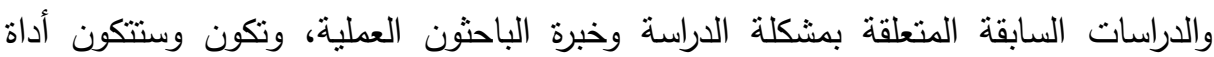

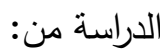

$$
\text { الجزء الأول: ويشمل (البيانات الاساسية). }
$$

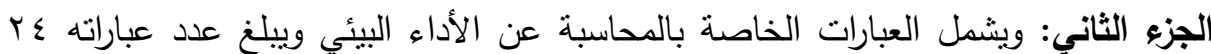

$$
\text { عبارة، مقسمة على ثلاث أبعاد. }
$$

الجزء الثالث: ويشمل العبارات الخاصة بجودة التقارير المالية وييلغ عدد عباراته ؟r عبارة مقسمة على ثلاث أبعاد، وبصورة أكثر تفصيلاً يوضح الجدول رقم (0) متغيرات البحث وعناصر قياسها ورموز أسئلتها التي تعكسها قائمة الاستيان.

\begin{tabular}{|c|c|c|c|}
\hline الاسئلة حدود & 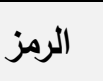 & الأبعاد & المتغيرات \\
\hline $1 \wedge-1$ & $\overline{\mathrm{X} 1}$ & معالجة المخلفات & \multirow{3}{*}{ المحاسبةِ عن الأدقاء البيئ } \\
\hline $17-9$ & $\mathrm{X} 2$ & التخلص من المخلفات & \\
\hline$T \varepsilon-1 V$ & $\overline{X 3}$ & الاهتماح بعلاج النلوث & \\
\hline$r_{T}-r_{0}$ & $\overline{\mathrm{Y} 1}$ & مصداقية التقاربر & \multirow{3}{*}{ جودة التقارير التابعالية } \\
\hline$\varepsilon \cdot-\mu r$ & $\overline{\mathrm{Y} 2}$ & ملاعمة التقارير & \\
\hline$\sum \wedge-\varepsilon$ & $\overline{\mathrm{Y} 3}$ & متخذى القرارات & \\
\hline
\end{tabular}
جدول رقم(0): يوضح متغيرات البحث وعناصر قياسها ورموز أسئلتها

وقد تم قياس استجابات أفراد العينة لفقرات المقياس، طبقا لمقياس ليكرت الخماسي كما

هو موضح في الجدول رقم (؟).

\begin{tabular}{|c|c|c|c|c|}
\hline غير اوافق & غير اوافق & محايل & موافق & موافق بشد \\
\hline 1 & $\bar{r}$ & $r$ & $\xi$ & 0 \\
\hline
\end{tabular}
جدول رقم(†): درجات مقياس ليكرت

وقد نم حساب مستوي الأهمية وفقاً للمعادلة التالية:

مستوي الأهمية = (الحد الأعلى للإجابة - الحد الأدنى للإجابة) ) الحد الأعلى للإجابة

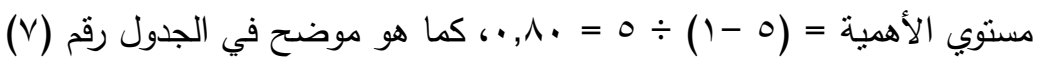




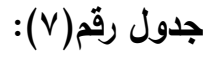

\begin{tabular}{|c|c|}
\hline مستوي الآهمية & المتوسط المرجح \\
\hline ضعنفة جدا & 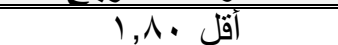 \\
\hline ضُعنفة & 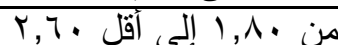 \\
\hline متوسطة & 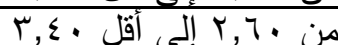 \\
\hline مرتفعة & من • ع, r, إلى أقل • • \\
\hline مرتفعة جدا & من • Y, ؛ إلى 0 \\
\hline
\end{tabular}

المعالِجات الإحصصائية المستخدِمة فِي الدّراسة: لتحقيق أهداف الدراسة وتحليل البيانات التي نم تجمعها، فقد تم استخدام الأساليب الإحصائية المناسبة باستخدام برنامج الإحصائي (Statistical Package for Social Science (SPS. Version 25 لتحليل

$$
\text { البيانات ومعالجاتها. }
$$

فيما يلي مجموعة من الأساليب الإحصائية المستخدمة في تحليل البيانات:

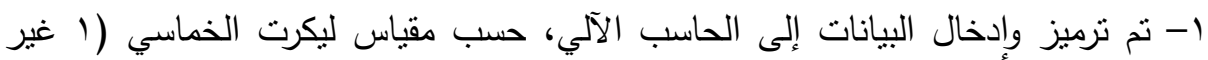
موافق بشدة، r غير موافق، r محايد، ع موافق، 0 موافق بشدة). r- تم حساب التكرارات والنسبة المئوية للتعرف على مفردات عينة الدراسة، وتحديد استجابات أفرادها تجاه عبارات أبعاد الدراسة.

r- تم استخدام المعالجات الإحصائية التالية للتأكد من صدق وثبات أداة الدراسة: معامل ارتباط بيرسون: التأكد من صدق الاتساق الداخلي للاسنبيان وذللك بإيجاد معامل

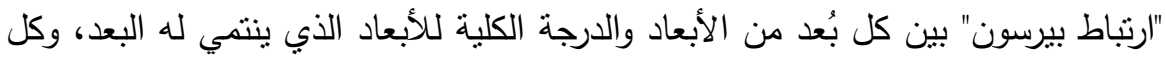

$$
\text { عبارة من العبارات مع البعد الذي تتنتي إليه العبارة. }
$$

معامل ارتباط سبيرمان براون للتجزئة النصفية المتساوية، ومعادلة جثمان للتجزئة النصفية غير المتساوية، ومعامل ألفا كرونباخ: للتأكد من ثبات أداة الدراسة. ع- المتوسط الحسابي Mean وذلك لمعرفة مدي ارتفاع أو انخفاض استجابات أفراد الدراسة

$$
\text { عن كل عبارة من عبارات متغيرات الدراسة الأساسية. }
$$

0- استخدام الانحراف المعياري (Standard Deviation) للتعرف على مدي انحراف استجابات أفراد الدراسة لكل عبارة من عبارات متغيرات الدراسة ولكل بُعد من أبعادها

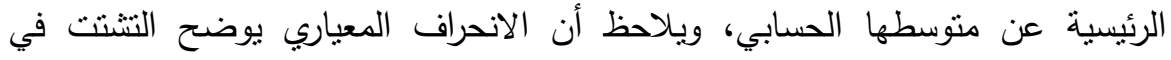

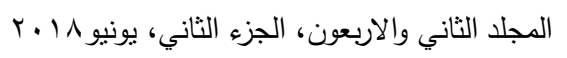


استجابات أفراد الدراسة لكل عبارة من عبارات متغيرات الدراسة إلى جانب أبعاد الدراسة،

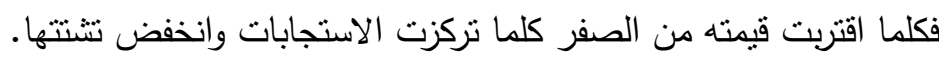

צ- اختبار كولومجروف سميرنوف لمعرفة نوع البيانات، هل تتبع التوزيع الطبيعي أم لا. V- نم استخدام المعالجات الإحصائية التالية لتحليل نتائج الدراسة الميدانية. المتوسطات الحسابية والانحرافات المعيارية والمتوسط المئوي المرجح في نتائج التحليل الوصفي للمتغيرات. تحليل الانحدار الخطي البسيط Simple Linear Regression Analysis لمعرفة أثر كل بُعد من أبعاد (المتغير المستقل) على (المتغير التابع).

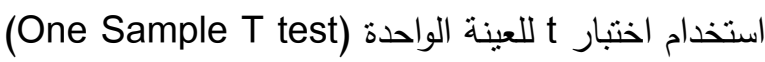

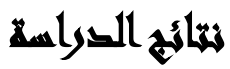

نتائج الإحصاء الوصفي لمتغيرات الاراسة:

\section{أولاً: نتائج التحليل الوصفي للمتغير المستقل (المحاسبة عن الأداء البيئي)} 1- نتائج التحليل الوصفي لعبارات بُعد (معالجة المخلفات)

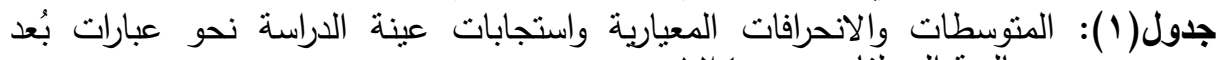

\begin{tabular}{|c|c|c|c|c|c|c|c|c|c|c|}
\hline \multirow[b]{2}{*}{ الأهمية } & \multirow[b]{2}{*}{ ألعبية } & \multirow[b]{2}{*}{ المئوي المتوسط } & \multirow[b]{2}{*}{ المعياري } & \multirow[b]{2}{*}{ سط المتو } & \multicolumn{5}{|c|}{ الاستجابات } & \multirow[b]{2}{*}{ لعبارة } \\
\hline & & & & & غوافير & موافيق & محايد & موافق & بثوة & \\
\hline مرتفعة & $\wedge$ & $\Lambda_{\cdot}, \varepsilon$. & $1, \cdot \vee \wedge$ & $\varepsilon, \cdot r$ & 0 & v & 19 & $\varepsilon r$ & 01 & 1 \\
\hline مرتفعة جدا & $r$ & $\Lambda V, r$ & •, Аrq & $\varepsilon, \Gamma_{4}$ & . & v & $\wedge$ & $\varepsilon r$ & TV & $r$ \\
\hline مرتفعة جدا & 7 & $\Lambda_{0, \varepsilon}$ &., 974 & $\varepsilon, Y V$ & $r$ & 7 & 10 & $r \varepsilon$ & TV & $r$ \\
\hline مرتفعة جدا & v & $\wedge \varepsilon, 7$ & $\cdot, 971$ & $\varepsilon, Y T$ & $\varepsilon$ & $r$ & $1 \pi$ & 纟o & 09 & $\varepsilon$ \\
\hline مرتفعة جدا & $\varepsilon$ & $\wedge \uparrow, \wedge$. & $1, .74$ & $\varepsilon, r \varepsilon$ & 1 & $r$ & 11 & rV & VV & 0 \\
\hline مرتفعة جدا & 0 & $\wedge 0, \wedge$ & .,9Y7 & $\varepsilon, r_{q}$ & $r$ & $r$ & 19 & rr & TV & 7 \\
\hline مرتفعة جدا & $r$ & $\wedge \vee, \ldots$ & $\cdot, \wedge \wedge \varepsilon$ & $\varepsilon, r_{0}$ & $r$ & $r$ & 17 & ro & 79 & v \\
\hline مرتفعة جدا & 1 & $\wedge \vee, \tau$ & $\cdot, \lambda \varepsilon r$ & $\varepsilon, \Gamma \wedge$ & 1 & $r$ & iv & r & VI & $\Lambda$ \\
\hline \multicolumn{2}{|c|}{ مرتفعة جدا } & 10,7 &., $00 Y \leq$ & $\varepsilon, r \wedge$. & \multicolumn{6}{|c|}{ إجمالى بُعد معالجة المخلفات } \\
\hline
\end{tabular}

* تم وضع ارقام العبارات بترتيب وجودها بقائمة الاستبيان في جميع جداول الدراسة.

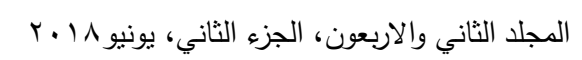


يُظهر الجدول السابق رقم (1) المتوسطات الحسابية والانحرافات المعيارية لاستجابات

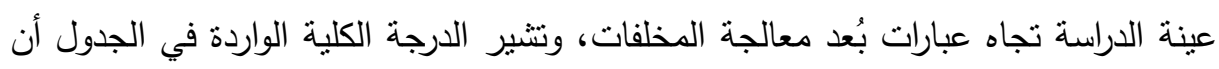

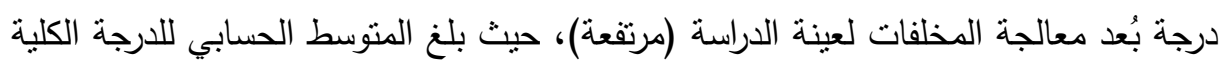

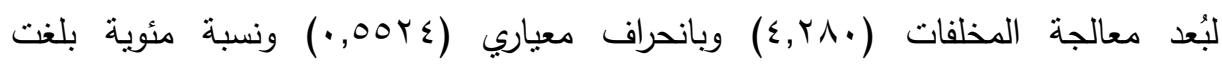

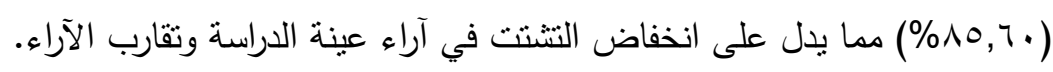
ويلاحظ في هذا الجدول أن العبارة رقم ((^) ندرك إدارة الثركة المزايا والمنافع البيئية

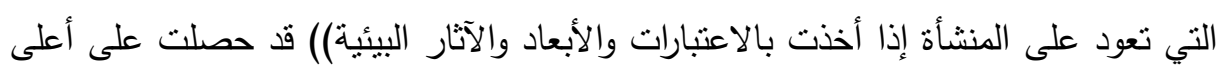

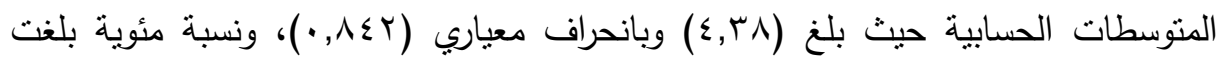
(\%^^,7.)

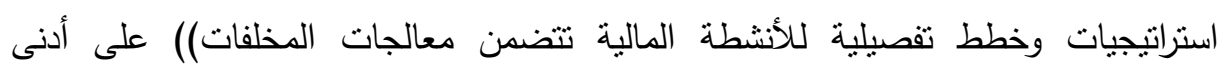

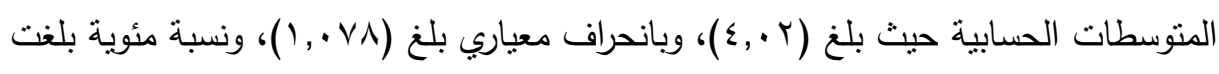

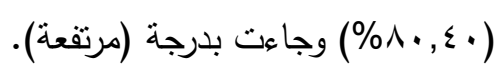

r - نتائج التحليل الوصفي لعبارات بُعد (التخلص من الت المخلفات).

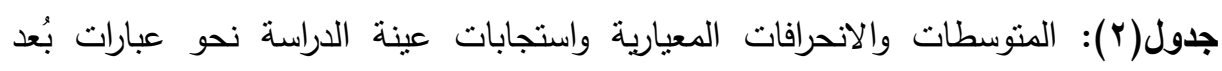

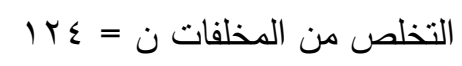

\begin{tabular}{|c|c|c|c|c|c|c|c|c|c|c|}
\hline \multirow[b]{2}{*}{ الأهمية } & \multirow[b]{2}{*}{ أهمبية } & \multirow[b]{2}{*}{ المئوي المتوجي } & \multirow[b]{2}{*}{ الانحراف } & \multirow[b]{2}{*}{ المتوسط } & \multicolumn{5}{|c|}{ الاستجابات } & \multirow[b]{2}{*}{ رقب } \\
\hline & & & & & غشير & غوافير & محايد & موافق & موافق & \\
\hline مرتفعة جدا & $r$ & $\wedge \uparrow, \uparrow$. & $1,1 \times 9$ & L,T & 7 & $\wedge$ & 7 & r & N & 9 \\
\hline مرتفعة جدا & 1 & $\wedge \vee, \wedge$. & $\cdot, \wedge 99$ & $\varepsilon, r q$ & r & $\varepsilon$ & 11 & $r \varepsilon$ & VT & 1. \\
\hline مرتفعة جدا & 0 & $\wedge \circ, \wedge$. & $\cdot, 971$ & $\varepsilon, r q$ & 1 & 11 & 0 & $\leqslant 1$ & 77 & 11 \\
\hline مرتفعة & $\wedge$ & $V r, \varepsilon$. & $1, r \wedge 4$ & $r, T V$ & 11 & $r$. & $r$ & 00 & ro & ir \\
\hline مرتفعة & 7 & $\wedge r, \wedge$. & $\cdot, 9 r \leq$ & $\varepsilon, 19$ & $r$ & $\Lambda$ & $r$ & 7. & 01 & $1 T$ \\
\hline مرتفعة جدا & $r$ & $\Lambda \vee, \ldots$ & $\cdot, \wedge \vee Y$ & $\varepsilon, r_{0}$ & . & 9 & 1 & $\leqslant 1$ & 71 & $1 \leq$ \\
\hline مرتفعة & v & V৭,7. & $1, r 07$ & $r, 91$ & $\wedge$ & 10 & 0 & rq & ov & 10 \\
\hline مرتفعة جدا & $\varepsilon$ & $\Lambda_{0}, \ldots$ & $1, \ldots 1$ & $\varepsilon, r_{0}$ & r & 11 & 0 & $\leq r$ & $7 \leq$ & 17 \\
\hline \multicolumn{2}{|c|}{ مرتفعة } & $\Lambda ז, T \leqslant$ & . $T \leqslant T$ & $\varepsilon, 1 \wedge r$ & \multicolumn{6}{|c|}{ إجمالي بُعد التخلص من المخلفات } \\
\hline
\end{tabular}

* تم وضع ارقام العبارات بترتيب وجودها بقائمة الاستنيان في جميع جداول الدراسة.

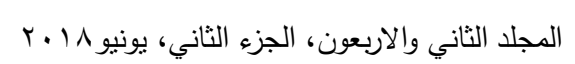


يُظهر الجدول السابق رقم (Y) المتوسطات الحسابية والانحرافات المعيارية لاستجابات عينة الدراسة تجاه عبارات بُعد التخلص من المخلفات، وتتثير الدرجة الكلية الواردة في الجدول

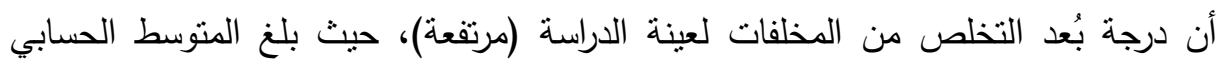

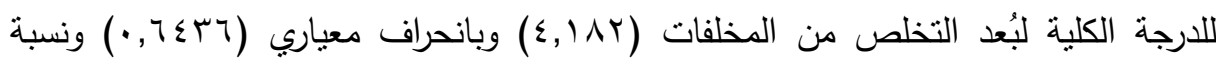

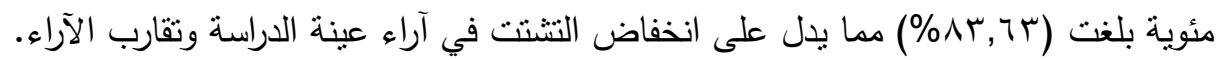

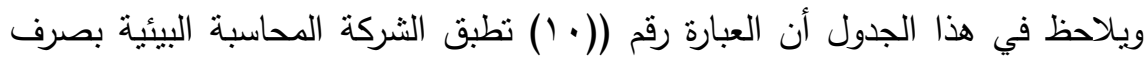

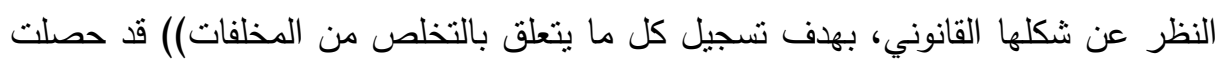

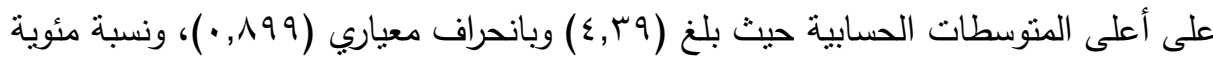

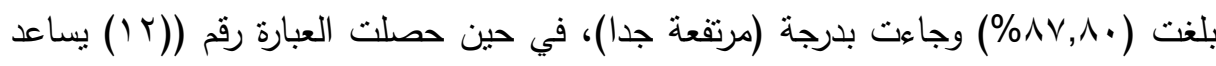
التخلص من المخلفات بطرقة امنة على تحقيق خطة التنمية المستدامة)) على أدنى

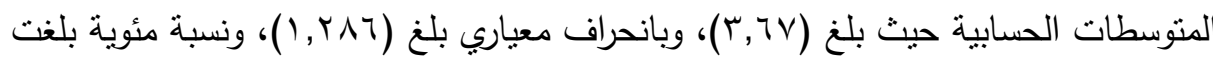

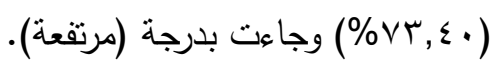
r- نتائج التحليل الوصفي لعبارات بُعد (الاهتمام بعلاج التلوث):

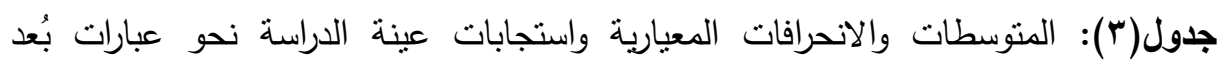

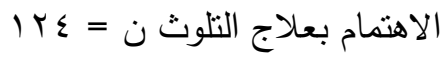

\begin{tabular}{|c|c|c|c|c|c|c|c|c|c|c|}
\hline \multirow[b]{2}{*}{ الأهمية } & \multirow[b]{2}{*}{ ألهيبة } & \multirow[b]{2}{*}{ المئوي المرجح } & \multirow[b]{2}{*}{ المعياري } & \multirow[b]{2}{*}{ المتوسط } & \multicolumn{5}{|c|}{ الاستجابات } & \multirow[b]{2}{*}{ العبارة } \\
\hline & & & & & غيثدة غوافق & غوافير & محايد & 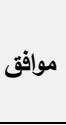 & بثوافق & \\
\hline 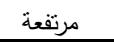 & $v$ & $\wedge r, \wedge$. & $\cdot, 9$, & $\varepsilon, 1 \mathrm{~V}$ & r & $\wedge$ & $r$ & $\pi$ & ะ9 & iv \\
\hline مرتفعة جدا & $r$ & $\Delta 4,7$. & $\cdot, \wedge \wedge 1$ & 足 & $\cdot$ & 9 & v & $\varepsilon r$ & 74 & 11 \\
\hline مرتفعة & $\wedge$ & $v q, \varepsilon$. & 1,Yצr & $r, q \vee$ & $\wedge$ & 10 & v & $r v$ & or & 19 \\
\hline مرتفعة جدا & $r$ & 10,7 &., $97 \mathrm{~V}$ & $\varepsilon, Y \wedge$ & r & $\wedge$ & 9 & $r q$ & 74 & r. \\
\hline مرتفعة جدا & 。 & $\wedge \varepsilon, \varepsilon$. & $1, \cdot 14$ & $\varepsilon, Y Y$ & 7 & v & 。 & $\varepsilon r$ & $T \varepsilon$ & ri \\
\hline مرتفعة جدا & 7 & $\wedge r, \wedge$. & $\cdot, \wedge \uparrow \wedge$ & $\varepsilon, 19$ & $\cdot$ & 7 & 19 & «o & $0 \leqslant$ & r \\
\hline مرتفعة جدا & 1 & $\Delta \vee, 7$. & $\cdot, V Y A$ & $\varepsilon, \Gamma \wedge$ & . & . & 11 & «1 & 70 & r \\
\hline مرتفعة جدا & $\varepsilon$ & $\wedge \varepsilon, \wedge$. & $1, .0 \leqslant$ & $\varepsilon, Y \varepsilon$ & $\varepsilon$ & v & Ir & $r$ & $\pi$ & $r \leq$ \\
\hline \multicolumn{2}{|c|}{ مرتفعة جدا } & $\Lambda \varepsilon, \varepsilon Y$ & & $\varepsilon, Y Y)$ & \multicolumn{6}{|c|}{ إجمالي بُعد الاهتمام بعلاج التلوث } \\
\hline
\end{tabular}

* تم وضع ارقام العبارات بترتيب وجودها بقائمة الاستبيان في جميع جداول الدراسة. 
يُظهر الجدول السابق رقم (r) المتوسطات الحسابية والانحرافات المعيارية لاستجابات عينة الدراسة تجاه عبارات بُعد الاهتمام بعلاج التلوث، وتتثير الدرجة الكلية الواردة في الجدول

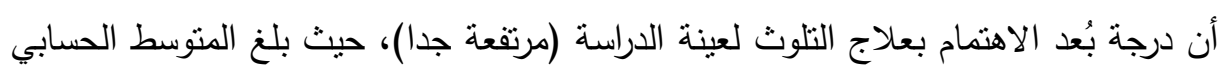

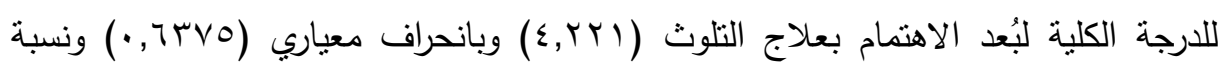

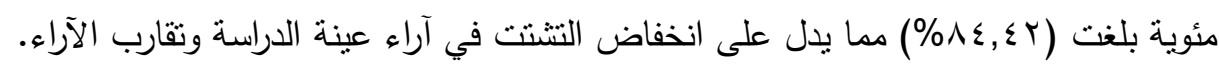

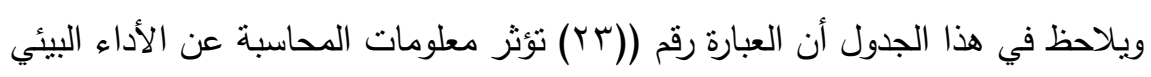
التي تقدمها الشركة بالإيجاب علي سمعة وربحية الثركة)) قد حصلت على أعلى المتوسطات

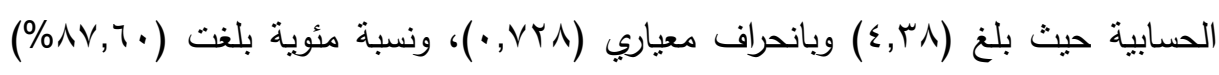
وجاءت بدرجة (مرتفعة جدا)، في حين حصلت العبارة رقم (9 (19) يتطابق تحليل وقياس تكلفة

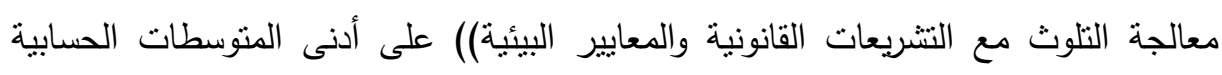

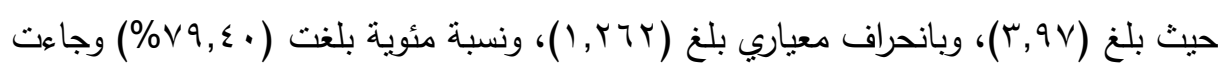

$$
\text { بدرجة (مرتفعة). }
$$

ثانياً: نتائج التحليل الوصفي للمتغير التابع (جودة التقارير المالية): ا- نتائج التحليل الوصفي لعبارات بُعد (مصداقية التقارير)

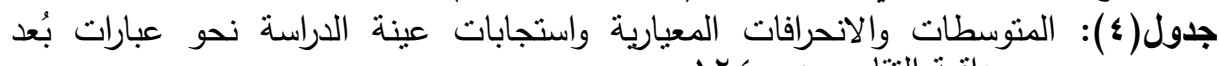

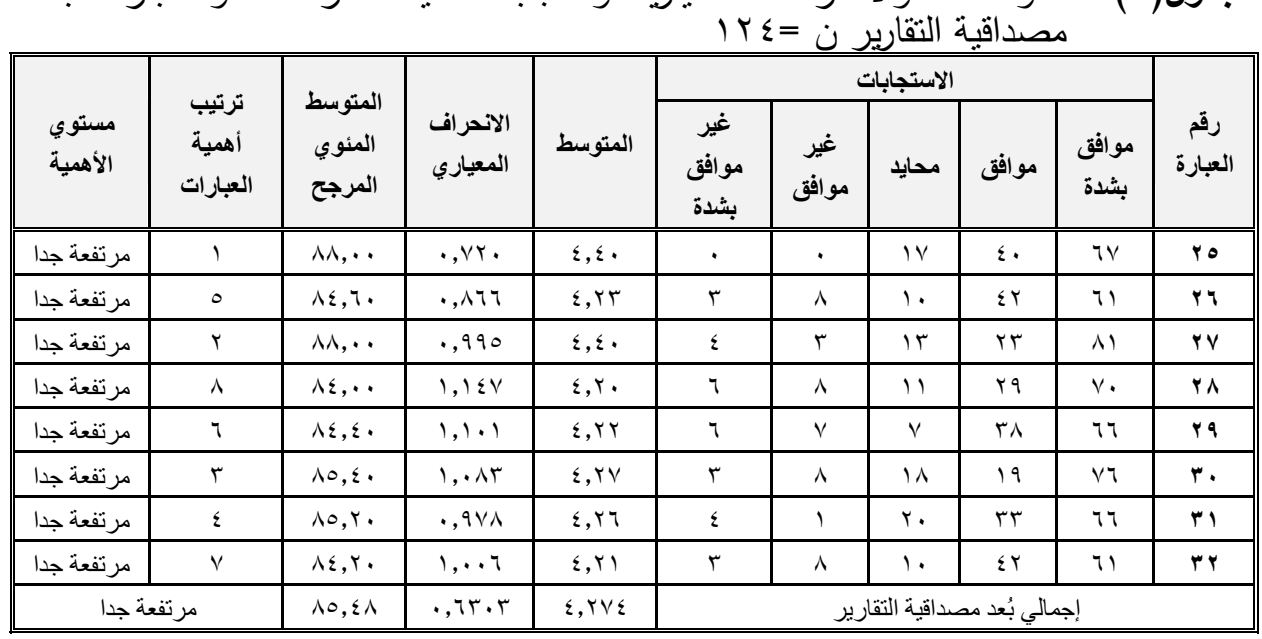

* تم وضع ارقام العبارات بترتيب وجودها بقائمة الاستبيان في جميع جداول الدراسة.

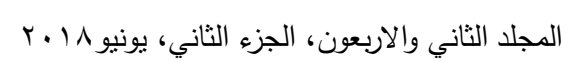


يُظهر الجدول السابق رقم (ع) المتوسطات الحسابية والانحرافات المعيارية لاستجابات

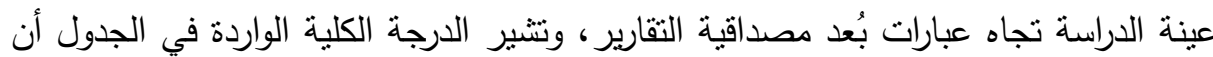

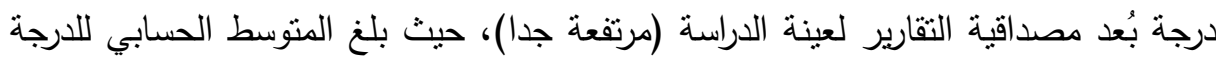

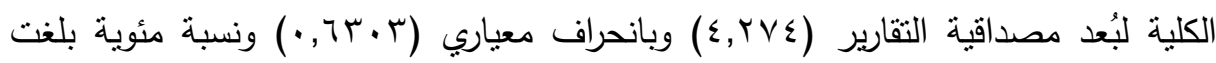

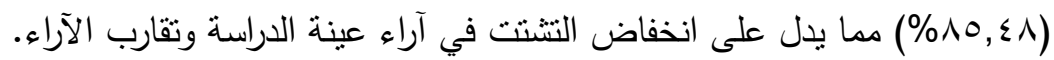

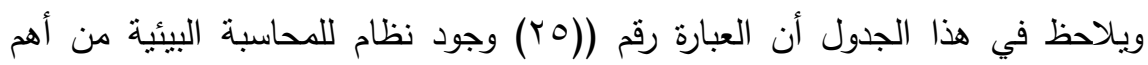

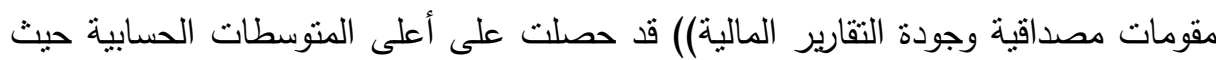

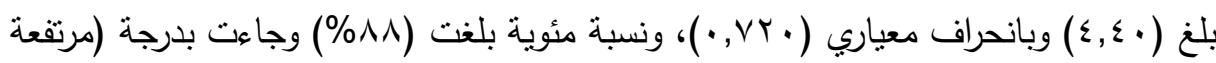

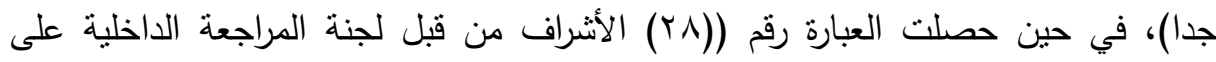
عملية اعداد التقارير المحاسبية والقوائم المالية يزيد من مصداقية القوائم المالية)) على أدنى

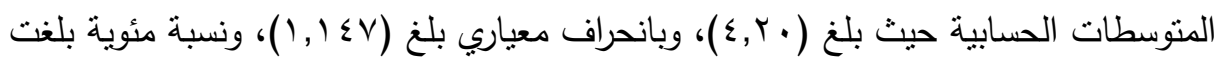

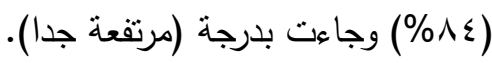

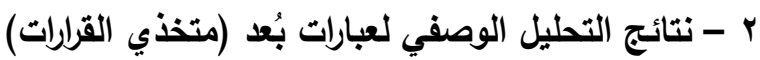

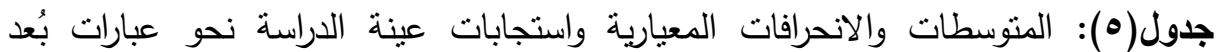

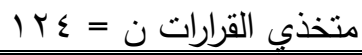

\begin{tabular}{|c|c|c|c|c|c|c|c|c|c|c|}
\hline \multirow[b]{2}{*}{ مستوية } & \multirow[b]{2}{*}{ ألهبية } & \multirow[b]{2}{*}{ المئوي المتوسط } & \multirow[b]{2}{*}{ الانحراف } & \multirow[b]{2}{*}{ المتوسط } & \multicolumn{5}{|c|}{ الاستجابات } & \multirow[b]{2}{*}{ رقبارة } \\
\hline & & & & & غيثدة غوافق & غو غير & محايد & موافق & بثدة & \\
\hline مرتفعة & $\wedge$ & $V V, \varepsilon$. & 1, ITV & $r, A Y$ & ir & ir & 17 & $r \varepsilon$ & 7. & \&1 \\
\hline مرتفعة & $\varepsilon$ & $\Delta r, r$. & $\cdot, 941$ & $\{, 11$ & . & ir & 1. & $0 \leqslant$ & $\varepsilon \wedge$ & $\varepsilon r$ \\
\hline مرتفعة & $\mathrm{v}$ & $\vee \wedge, \ldots$ & $\cdot, 1 \cdot \mathrm{VA}$ & $r, q$. & $\varepsilon$ & 9 & rv & rq & $\varepsilon_{0}$ & $\varepsilon r$ \\
\hline مرتفعة & 。 & $\Lambda 1, r$. & $1,10 \mathrm{~V}$ & $\varepsilon, .4$ & 7 & 9 & 17 & $r \varepsilon$ & 09 & $\varepsilon \varepsilon$ \\
\hline مر تفعة جدا & $r$ & $\wedge 0, \wedge$. & $1, .0 \mathrm{~V}$ & $\varepsilon, r q$ & 。 & 7 & $\wedge$ & $r \varepsilon$ & vi & $\varepsilon_{0}$ \\
\hline مرتفعة & 7 & $\Lambda_{\cdot}, \mathrm{r}$. & $1, r \mid r$ & $\varepsilon, .1$ & 9 & 7 & 11 & זr & 01 & $\leqslant 7$ \\
\hline مر تفعة جدا & r & ᄉт, . & 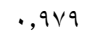 & $\varepsilon, r$. & $r$ & 。 & ir & $r \varepsilon$ & 79 & $\varepsilon v$ \\
\hline مر تفعة جدا & 1 & $\wedge \uparrow, \wedge$. & ·, AVr & $\varepsilon, \Gamma \varepsilon$ & r & $r$ & ir & «) & 77 & «^ \\
\hline \multicolumn{2}{|c|}{ 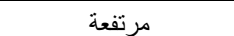 } & $\Delta r, \mid \wedge$ & . $\neg \wedge \leqslant$. & $\varepsilon, 1.9$ & \multicolumn{6}{|c|}{ إجمالى بُعد متخذي القر ارات } \\
\hline
\end{tabular}

* تم وضع ارقام العبارات بترتيب وجودها بقائمة الاستبيان في جميع جداول الدراسة. 
يُظهر الجدول السابق رقم (0) المتوسطات الحسابية والانحرافات المعيارية لاستجابات

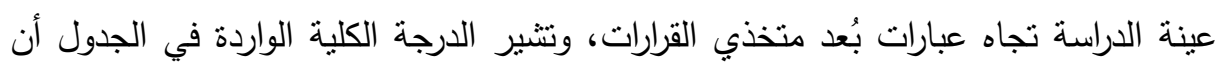

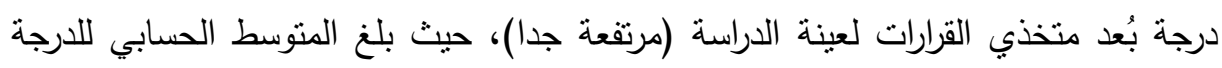

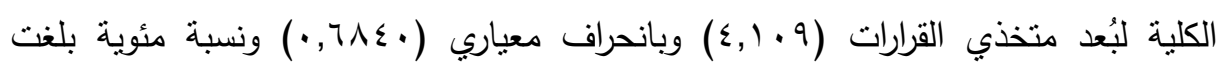

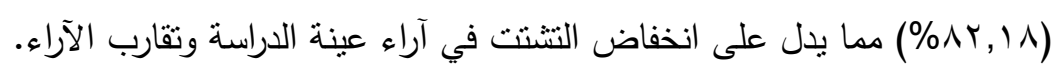

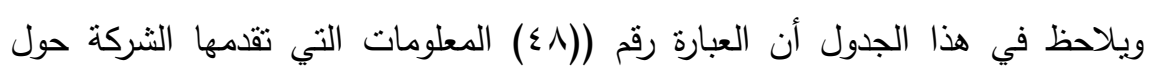

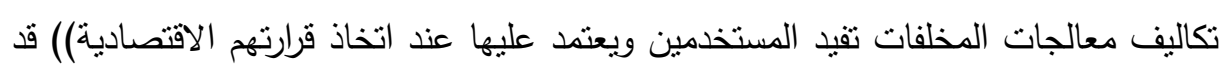

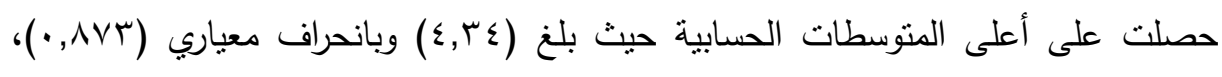
ونسبة مئوية بلغت (•^,^^\%) وجاءت بدرجة (مرتفعة جدا)، في حين حصلت العبارة رقم

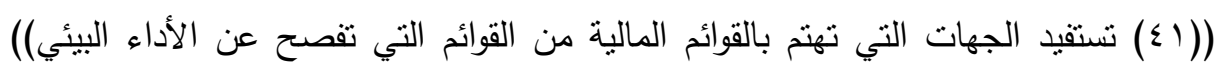

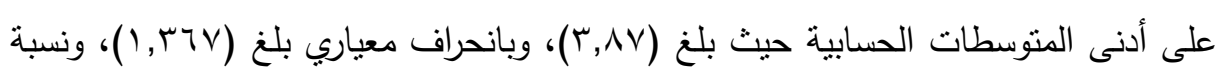

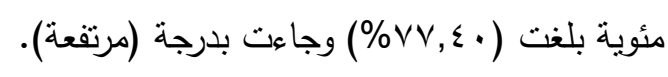

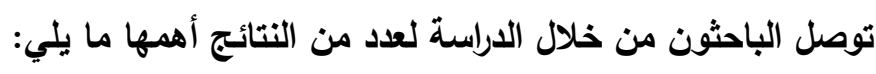

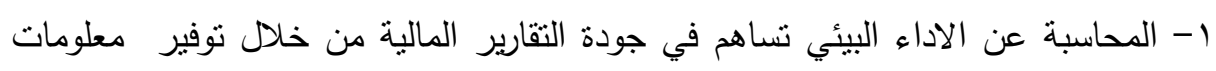
عن التكاليف المتعلقة بتقليل اضرار المخلفات.

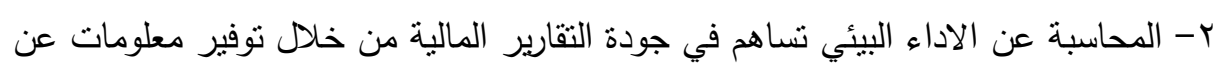
التكاليف الناتجة عن اعادة التدوير للمخلفات.

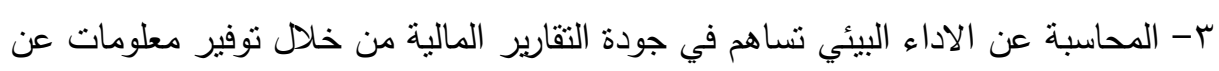

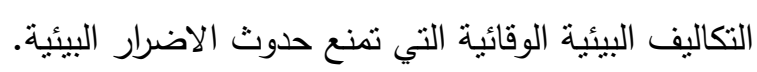

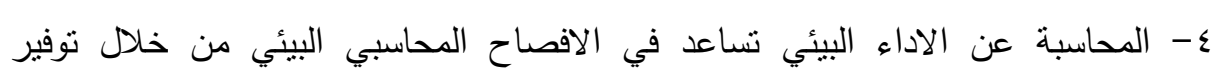
معلومات عن الاصول الثابتة البيئية في المنشأة.

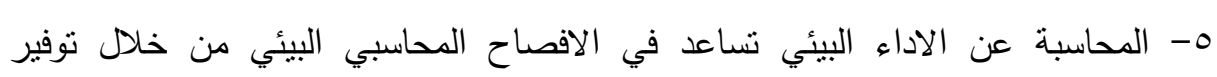
معلومات عن الالتزام البيئي للمنشأة وفقا لقوانين ولوائح حماية البيئة. 


\section{الليوكيايت}

في ضوء نتائج الدراسة المشار إليها، توصل الباحثون إلى عدد من التوصيات من أهمها:

1- تطبيق المحاسبة عن الاداء البيئي في الثركات لتوفير معلومات متعلقة باتخاذ القرارات

r- الالتزام بجودة التقارير المالية من خلال نطبيق المحاسبة عن الاداء البيئي التي توفر

$$
\text { معلومات الجودة العرض والافصاح. }
$$

r - تتجيع الشركات على تطبيق المحاسبة عن الاداء البيئي من خلال تقديم الإعفاءات

الضريبية للشركات التي تقوم بتطبيقها وذللك تتجيعاً لها على حماية البيئة.

ع - العمل على زيادة الوعي البيئي للمجتمع واصدار قوانين تلزم المنشآت خاصة المنشآته الصناعية بتحمل مسؤوليتها تجاه البيئة.

ه- تدريب المحاسبين والمختصين بالمؤسسات من خلال عمل دورات تؤهلهم لقياس الأثار

$$
\text { البيئية والإفصاح عنها في القوائم المالية. }
$$

צ- ضرورة إصدار التشريعات والقوانين والتعليمات التي توجب المؤسسات بالتزام المعايير

$$
\text { الدولية التي لها علاقة بحماية البيئة والمجتمع من التلوث. }
$$

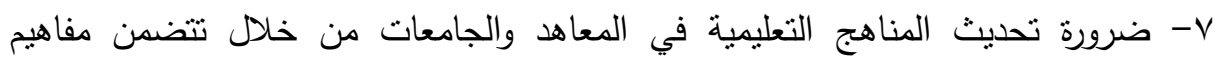
المحاسبة البيئية وأسس قياس وتحليل التكاليف البيئية.

\section{call}

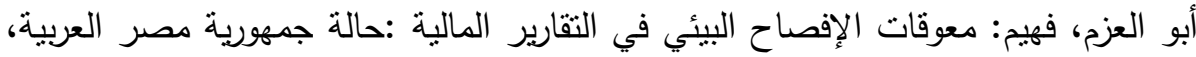

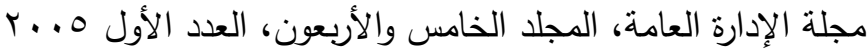

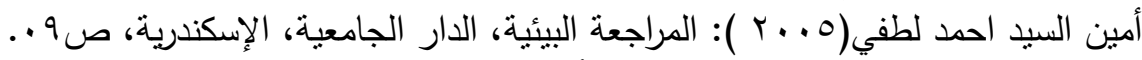

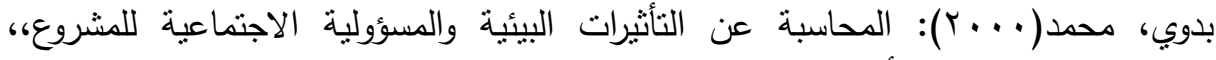

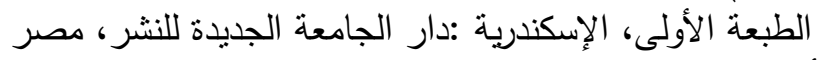

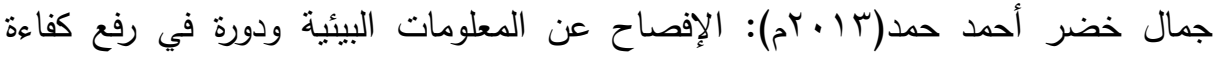

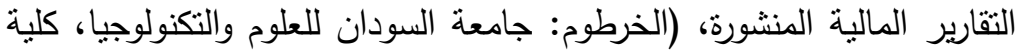
الدراسات العليا، رسالة ماجستير غير منشورة 


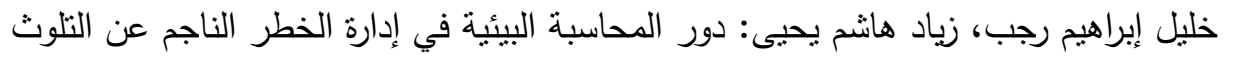

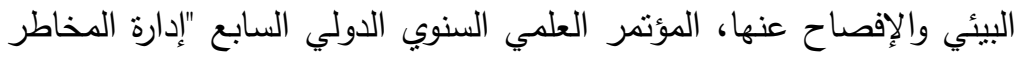

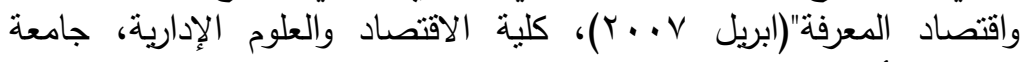

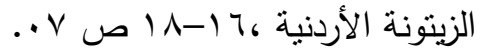

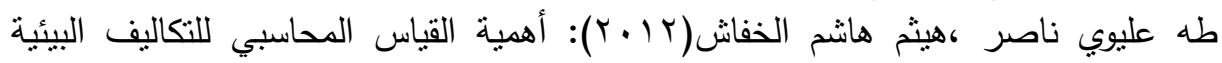

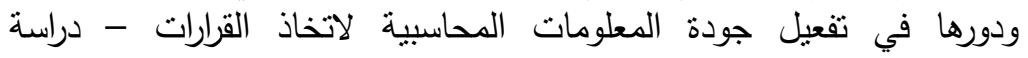

استطلاعية لآراء عينة من المنيآت الصنات الصناعية بمدينة الموصل، مجلة الإدارة

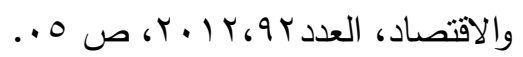

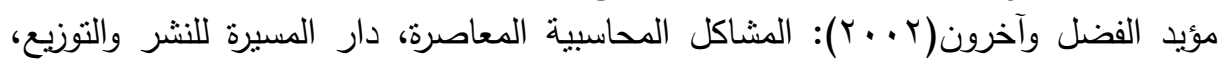

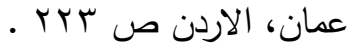

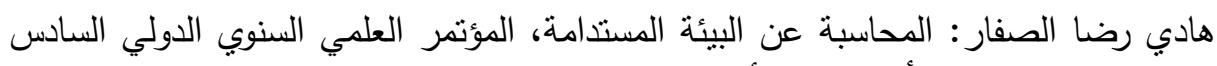

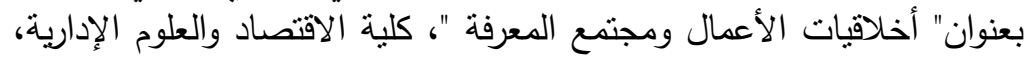

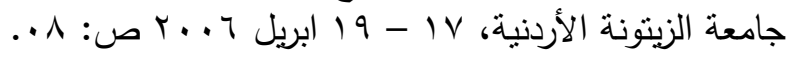

Abedel-Naser Nour (2003): Alok Kumar Pramanik: Impact of Environmental Accounting on Productivity, Environmental Accounting and Reporting, p 473-474.

Roger L.Burritt, (2004): Business Strategy and the environment, Vol,13, Issue 1, p:13.

Jennifer Oullette, (1996): Environmental Accounting Chemical Marketing Rebort, Vol,250 issue 3 เp:19.

Ball, Amanda, seal, will, (2005): Social justice in a cold climate: Could social accounting make a difference?, Elsevier.

Ball, Amanda, (2006): Environmental accounting as workplace activism,New Zealand, Vol. 4, No.5,

Connor, O.,(2006): Empirical Research in Social and Environmental Accounting: A Metareview. 


\title{
IMPACT OF ACCOUNTING OF ENVIRONMENTAL PERFORMANCE ON QUALITY OS FINANCIAL REPORTS AN APPLIED STUDY ON OILS AND DETERGENTS IN SOHAG
}

Khatab, G. S. A. ${ }^{(1)}$; El-shehat, Nehal, M. F. ${ }^{(2)}$ and Rashid, Z. A. M. ${ }^{(3)}$

1) Faculty of Commerce, Ain Shams University.2) Institute of Environmental Studies and Research, Ain Shams University 3) Ministry of Youth.

\begin{abstract}
The objective of this study is to focus on accounting for environmental performance, which will contribute to improving the welfare of society and reducing the social, economic and environmental problems. The study followed the analytical descriptive method. The sample consisted of 130 employees of the company of oils and detergents in Sohag at various levels to ascertain the reality of their performance For their role, and to explore their views on the impact of accounting for environmental performance on the quality of financial reports, and the problems they face. The researchers used the data obtained from the cases of study, through observation and in-depth interview and the use of specialists, The study concluded that the accounting should not only be limited to the financial statements, but should be concerned with the social and environmental dimension, which led to the need for an accounting system that produces information related to the social and environmental responsibility of the economic institutions. The importance of the environmental performance of the institution as one of the important axes in evaluating

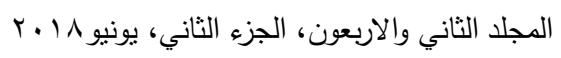


its performance, considering that the quality of environmental performance significantly affects the rest of its other balanced performance; Giving institutions that preserve the environment preferential tax treatment in terms of exemption or reduction of taxes Imposed on them, in order to encourage them to protect the environment. 